J Magn Reson Imaging. 2017 November ; 46(5): 1247-1262. doi:10.1002/jmri.25711.

\title{
PET/MRI: Where Might It Replace PET/CT?
}

Eric C. Ehman, MD1, Geoffrey B. Johnson, MD,PhD', Javier E. Villanueva-Meyer, MD², Soonmee Cha, MD $^{2}$, Andrew Palmera Leynes, $\mathbf{M S}^{2}$, Peder Eric Zufall Larson, PhD $^{2}$, and Thomas A. Hope, MD2, ${ }^{*}$

${ }^{1}$ Department of Radiology, Mayo Clinic, Rochester, Minnesota, USA

${ }^{2}$ Department of Radiology and Biomedical Imaging, University of California, San Francisco, California

\section{Abstract}

Simultaneous positron emission tomography and MRI (PET/MRI) is a technology that combines the anatomic and quantitative strengths of MR imaging with physiologic information obtained from PET. PET and computed tomography (PET/CT) performed in a single scanning session is an established technology already in widespread and accepted use worldwide. Given the higher cost and complexity of operating and interpreting the studies obtained on a PET/MRI system, there has been question as to which patients would benefit most from imaging with PET/MRI versus PET/CT. In this article, we compare PET/MRI with PET/CT, detail the applications for which PET/MRI has shown promise and discuss impediments to future adoption. It is our hope that future work will prove the benefit of PET/MRI to specific groups of patients, initially those in which PET/CT and MRI are already performed, leveraging simultaneity and allowing for greater degrees of multiparametric evaluation.

The fusion of functional information gathered from positron emission tomography (PET) with anatomic information obtained using computed tomography (CT) has led to rapid growth in the use of PET/CT since its introduction to clinical practice. PET/CT systems using 18F-fluorodeoxyglucose (FDG) PET to measure metabolic activity are both beneficial to patients and cost effective for several oncologic indications ${ }^{1-9}$ and show promise in the evaluation of a wide range of other conditions, including infection/inflammation, ${ }^{10-12}$ cardiac imaging, ${ }^{13}$ and neurological function. ${ }^{14-16}$ FDG uptake is an important discriminating factor in the evaluation of potentially malignant cells. ${ }^{17}$ Additionally, there is a host of newly developed PET radionuclides which are being used to image neuroendocrine tumors, prostate cancer, and for a variety of neurologic indications.

Combined PET and MRI is an emerging technology that aims to capitalize on the inherent advantages of MRI, including increased soft tissue contrast and lack of ionizing radiation exposure. ${ }^{18-22}$ Despite the availability of PET/MRI, there have been some initial questions as to which indications are most appropriate for its use given increased cost and complexity of operation compared with PET/CT.

\footnotetext{
*Address reprint requests to: T.H., 505 Parnassus Avenue M361, San Francisco, CA 94143. thomas.hope@ucsf.edu. Level of Evidence: 5
} 


\section{PET/CT Versus PET/MRI}

\section{Wide Spread Availability}

The first integrated whole body PET/MRI systems were installed in 2010. Currently, there are approximately $30 \mathrm{PET} / \mathrm{MRI}$ scanners in the United States, compared with over 1600 PET/CT systems. PET/MRI systems are more costly than PET/CT systems due to the inherent costs of MRI versus CT technology and the fact that a great deal of research and development has recently been required for the initial development of PET/MRI. PET/CT systems are currently much more widely available than PET/MRI systems, although this may change with time as adoption increases. An overview of PET/ CT versus PET/MRI is shown in Table 1.

\section{Experience in Acquisition and Interpretation}

Radiologists and Nuclear Medicine physicians are experienced in the interpretation of PET/CT studies, understand common artifacts, and have established systems and protocols to efficiently prepare and image patients. Similarly, referring clinicians are familiar with and have established indications for which they order PET/CT and feel confident in the results obtained from the test. PET/MRI requires interpreting physicians to be trained in the intricacies of MR imaging, appropriate indications for PET/MRI, and the current limitations of the combined modality. There are a relatively small number of available physicians with subspecialty training in both MRI and nuclear medicine. In addition to the expertise of radiochemists and PET physicists, a successful PET/MRI practice requires the close involvement of MRI physicists to optimize pulse sequences and minimize artifacts in image acquisition. It is anticipated that as PET/ MRI technology expands and user experience grows, these issues will decrease over time.

\section{Technologist Training}

In most states, technologists are required to be certified in nuclear medicine to administer radioactive isotopes for medical imaging. With PET/MRI, the most complicated portion of the examination is the acquisition of the MR images, necessitating significant technologist training to optimize exam quality. Cross-training nuclear medicine and MRI technologists, although perhaps ideal, to this point has been uncommon and may serve as a challenge in fully implementing successful clinical PET/MRI programs. There is a need for new joint training programs to increase the pool of trained PET/MRI technologists, which currently do not exist. Developing appropriate coursework through the Society of MR Radiographers and Technologists and the SNMMI Technologists Section will be important steps in appropriate training.

\section{Quantitative Accuracy}

Quantitative accuracy in PET requires many components. Key among these are accurate attenuation correction maps and optimized and proven reconstruction techniques.

Attenuation correction accounts for the fact that photons arising from structures deeper in the body are more likely to be attenuated than those arising from the surface. CT provides 
patient-specific attenuation correction maps using the calculated reconstruction of internal density inherent to the process of CT imaging.

MRI, on the other hand, cannot directly assess tissue density and in particular has difficulty imaging the lung and bones; therefore, creating an accurate attenuation correction map remains elusive. ${ }^{23}$ New pulse sequences are being developed to improve attenuation maps, but have not yet become widely validated, broadly available, or FDA approved. ${ }^{24,25}$ Established reconstruction algorithms have been developed in PET/CT, allowing for reproducible quantification as evaluated with specialized phantoms ${ }^{26,27}$; however, this remains a challenge on PET/MRI systems because these phantoms are not usable in the PET/MRI environment which requires alternative materials. ${ }^{28,29}$

Recent studies directly comparing PET/CT SUV measurements with those obtained at PET/MRI have had mixed results, possibly due to time-related uptake and decay issues that manifest in sequential scanning with both modalities after a single injection. ${ }^{30}$ Other studies have demonstrated improved quantitative accuracy using the newest time of flight PET/MRI detector technology. ${ }^{31}$ Future work needs to be done to standardize protocols and harmonize quantification of radiotracer uptake in the setting of PET/MRI, similar to what has been performed in PET/CT. Additionally, PET/ MRI specific phantoms need to be developed in order to test the reproducibility of quantitative accuracy across scanners and sites.

\section{Patient Comfort}

Neglect of patient comfort can lead to dissatisfaction from both patients and referring physicians. The bore diameter of the two commercially available PET/MRI systems is 60 $\mathrm{cm}$, while the typical bore diameter of a PET/CT is $70 \mathrm{~cm}$ or greater. Claustrophobia is not typically an issue with PET/CT, but many patients do experience claustrophobia with PET/ MRI. This is likely due to a combination of the relatively narrower and longer bore and the use of whole-body anterior surface coils and a head coil required for the MRI portion of the exam. This problem is compounded when imaging particularly large or obese patients, who may not physically fit in a PET/MRI. PET/CT systems are also much quieter than a PET/ MRI, allowing patients to listen to ambient music during the study. The rapidly changing gradients on the MRI create loud noises, requiring patients to wear earplugs and may result in patient dissatisfaction.

Finally, PET/CT protocols are much faster. Most applications on PET/MRI are designed to take advantage of multi-sequence MRI, resulting in studies that may exceed an hour in length, compared with PET/CT studies that are usually completed within 30 min. Many cancer patients are simply unable to remain supine and still for more than an hour due to pain. Simplified MRI protocols may allow PET/MRI to approach or rival PET/CT for speed, ${ }^{32-35}$ but those protocols often do not take full advantage of PET/ MRI and may fail to justify the additional expense of PET/ MRI. One time saving advantage of PET/MRI is the longer z-axis coverage, allowing more of the patient's body to be imaged at each bed position, thus accelerating the PET acquisition. However, this does little to shorten the MRI component of the examination. Improving the patient experience through development of less claustrophobic coils, more comfortable table surfaces, and improved audio/visual equipment will be essential to the success of PET/MRI in the future. 


\section{PET Acquisition}

In addition to offering the latest in detector technology, combined PET/MRI systems may acquire higher quality PET images due to longer time available for acquisition and the ability to use MRI respiratory gating information to improve PET data. While PET/CT certainly possesses an advantage in terms of overall acquisition time due to the rapid nature of CT scanning, the extra time spent on MRI image acquisition is by no means wasted. Typically, the majority of MRI sequences are obtained in the anatomic region of interest (pelvis for prostate cancer or rectal cancer, abdomen for liver lesion evaluation); therefore, extra time spent at this bed position permits a longer PET acquisition providing increased detector counts and improved image quality (Fig. 1). Additionally, because MRI sequences are typically obtained during breath-holds or using respiratory gating, PET data can be filtered and reconstructed only with data at motion free time points, allowing for decrease in motion artifact within images (Fig. 2) and improved colocalization with anatomic MRI images.

\section{Current Applications of PET/MRI}

In general, applications for which PET/MRI is initially being used are those in which sequential PET and MRI are the standard of care. Applications capitalize on the inherent advantages of MRI versus CT, such as increased soft tissue contrast, use of hepatocyte specific contrast agents, and the ability to perform multiparametric evaluation including the quantification of radiotracer uptake combined with ADC values. ${ }^{36}$

\section{Neurological}

MR imaging is the accepted test of choice for most non-traumatic, anatomic neurological indications; therefore, it is logical that PET/MRI may offer advantages over PET/CT in the diagnosis or characterization of many conditions.

Co-registration of independently performed brain FDG PET and MRI scans has been shown to be beneficial in the management of cortical dysplasias, ${ }^{37}$ tuberous sclerosis, ${ }^{38}$ and temporal lobe epilepsy ${ }^{39}$; therefore, simultaneous acquisition of PET and MRI data would offer similar or improved value with increased efficiency and convenience for the patient when compared with MRI and PET examinations performed independently.

There is strong evidence to support the use of PET in the evaluation of primary brain tumors. The most common pattern of recurrence in patients with glioblastoma multiforme (GBM) following gross total resection is the reappearance of a tumor along the surgical margin. ${ }^{40-42}$ Current MR imaging techniques are neither sensitive nor specific for the detection of small foci of recurrent disease and mimics such as inflammation or radiation necrosis may be mistaken for recurrence. Prior studies have shown that functional or physiologic parameters interrogated using PET may improve diagnostic accuracy. These include FDG to evaluate metabolism ${ }^{43,44}$ and 3-deoxy-3-18F-fluorothymidine (FLT) to gauge mitotic activity to differentiate between viable tumor and radiation necrosis. ${ }^{45} 18 \mathrm{~F}$-fluoromisonidazole (FMISO) has been used to detect cellular hypoxia, a poor prognostic indictor in the progression of GBMs. ${ }^{46}$ 
Amino acid tracers and analogues such as, 11C-Methionine (MET), 18F-Fluoroethyl-Ltyrosine (FET), 3,4-dihydroxy-6-(18)F-fluoro-L-phenylalanine (FDOPA) (Fig. 3), and a synthetic L-leucine analog (anti-1-amino-3-18F-fluorocyclobutane-1-carboxylic acid [FACBC]) have been used to localize and characterize pretreatment and postsurgical residual disease. ${ }^{47-49}$ Likely on account of the dominance of MRI over CT in the evaluation of nontraumatic neurologic indications, there is limited existing evidence to directly compare PET/MRI with PET/CT using many of the previously aforementioned agents. Nevertheless, it is expected that fusion of functional information gained using a wide variety of PET tracers with the strengths of anatomic data obtained at MRI will help to leverage the inherent advantages of each technology and provide more specific multiparametric evaluation of pathology with precise anatomic localization.

\section{Head and Neck}

FDG PET/CT systems are routinely used to assess local extent of disease, detect distant metastases, and to monitor response to therapy in squamous cell carcinoma of the head and neck. In many practices, MRI is used for the characterization of local disease following surgery and radiation therapy. Therefore, these patients often undergo sequentially performed MR and PET/CT studies of the head/neck. Initial experience with the use of simultaneously acquired PET and MRI data for the evaluation of head and neck cancer (Fig. 4) has been promising. ${ }^{50-52}$ MRI may offer specific benefits over CT in combined PET acquisitions due to the added value of multiparametric evaluation possible using diffusion weighted imaging (DWI). A recent report shows a high degree of correlation between glucose metabolism, diffusion restriction, and histopathological features of aggressive tumors. ${ }^{53}$ There is also evidence that PET/MRI may offer benefit in the challenging situation of evaluating a patient with cancer of unknown primary, with a recent study demonstrating increased conspicuity of previously undiagnosed head and neck primary tumors at PET/MRI compared with PET/CT. ${ }^{54}$

\section{Thoracic}

Imaging of lung tissue is difficult using MRI due to low proton density, rapid loss of signal secondary to field inhomogeneity, and lung motion during the respiratory cycle. While not ideal for imaging of the lung parenchyma itself, PET/MRI has shown promise in both the characterization of primary bronchogenic tumors as well as the determination of their extent and metastases. ${ }^{55,56} \mathrm{~A}$ contrast enhanced MRI of the head is required for staging of patients with advanced lung cancer; therefore, an FDG study including a brain MRI tailored to detect metastases in this subgroup of patients who already have diagnostic breath-hold CT imaging of the chest offers additional information bundled in to one examination. Other proposed benefits of PET/MRI over PET/CT for the staging of non-small-cell lung cancer include improved delineation of chest wall, diaphragm, or mediastinal invasion to affect T-stage, greater sensitivity for nonenlarged but suspicious FDG avid or DWI hyperintense mediastinal lymph nodes to alter $\mathrm{N}$-stage, and simultaneous MRI evaluation of the liver and adrenals which may change M-stage (Fig. 5). ${ }^{57-59}$

Another challenge in PET/MRI has been the detection of small pulmonary nodules. Recent studies have suggested that PET/MRI may fail to detect small pulmonary nodules $(<5-10$ 
$\mathrm{mm}$ ) that are visible at PET/CT in oncology patients, potentially impacting treatment decisions. ${ }^{60-62}$ New approaches such as ultrashort echo time sequences (UTE) have been proposed to improve detection of pulmonary nodules measuring as small as $6 \mathrm{~mm}$ at MRI, but have yet to enter general clinical practice. ${ }^{63}$ While detection of 6-mm nodules may be sufficient for the stratification of bronchogenic carcinoma using Lung-RADS, ${ }^{64}$ patients with other types of cancers may require evaluation and surveillance of even smaller nodules to discriminate benign nodules from early metastases, sometimes necessitating a dedicated inspiratory chest CT when PET/MRI or even PET/CT are performed. Dedicated breath-hold $\mathrm{CT}$ also provides additional value in terms of the appearance of surrounding lung parenchyma and a more accurate depiction of pulmonary nodule morphology and texture, features which may favor a benign or malignant etiology.

\section{Liver Tumors}

The initial evaluation of hepatic masses has typically been performed with multiphase CT or MRI of the liver using extracellular contrast agents. The most common use of PET/MRI of the liver is for the detection and characterization of hepatic metastases. Complete and accurate detection of hepatic metastases is particularly important in diseases such as colon or rectal cancer (Fig. 6) where therapies depend on the size and number of lesions. ${ }^{65}$ Using PET/MRI, there exists an opportunity to combine a diagnostic multiphase MRI of the liver, current standard of care, with a PET evaluation which may offer improved sensitivity and specificity in the liver more completely assessing both presence and viability of distant disease. Performing a diagnostic liver study also allows the use of a hepatobiliary contrast agents that have increased sensitivity for liver metastases. ${ }^{66}$

With hepatocellular carcinoma (HCC), PET has traditionally taken a secondary role, although there are recent studies have shown a potential diagnostic benefit for using a dualtracer PET protocol with 11C-acetate and FDG for characterization. ${ }^{67,68}$ FDG PET/CT also has a role in the evaluation of cholangiocarcinoma, both for recurrent disease at the location of treatment as well as for distant metastases. ${ }^{69}$ In cholangiocarcinoma, the primary tumor is often not appreciated and only the biliary strictures are seen to indicate the presence of the lesion. FDG PET often can depict the hypermetabolism that indicates the presence of a malignant tumor causing the stricture, although inflammation from recently placed biliary stents can complicate interpretation.

Determination of resectability of untreated pancreatic cancer is primarily guided by multiphase CT owing to the reliable contrast timing and high spatial resolution required for vascular evaluation; however, PET/MRI may serve as a useful adjunct for the detection of metastases while allowing simultaneous evaluation of the biliary system with MR cholangiopancreatography (MRCP) (Fig. 7). In cases of borderline resectable disease, the improvement of CT findings suggesting vascular involvement may lag the FDG findings, and it is hypothesized that PET/MRI evaluation following neoadjuvant chemo and radiation therapy may more quickly predict those patients who have adequately responded and are now eligible for resection.

PET agents targeting the somatostatin receptor on the cell surface such as 68Ga-DOTATATE and 68Ga-DOTA-TOC have been shown to be beneficial in the evaluation of patients 
with neuroendocrine tumors such as neuroendocrine pancreas cancer, small bowel carcinoid, pheochromocytoma, and paraganglioma. ${ }^{70-72}$ As neuroendocrine tumors frequently metastasize to the liver, somatostatin receptor PET combined with a hepatobiliary MRI may be particularly useful in the follow-up of these often indolent diseases (Fig. 8).

\section{Pelvic}

There are multiple applications within the male and female pelvis that should benefit from the added value that a concurrently performed targeted MRI would provide in a disease otherwise evaluated with PET/CT. These include cancers of the rectum, cervix, endometrium, ovaries, and prostate.

In patients with rectal carcinoma, focused pelvic MRI is essential for determining the primary tumor T-stage and for the detection of local nodal metastases to guide treatment. ${ }^{73}$ Select patients not initially eligible for surgery may undergo neoadjuvant chemotherapy and radiation before repeat evaluation with pelvic MRI to assess for resectability. ${ }^{74,75}$

Along these lines, multiple studies have shown a decrease in metabolism in treated tumors and that a measured decrease in tumor glucose uptake predicts long-term survival. ${ }^{76-78}$ Determining $\mathrm{N}$-stage is more difficult using anatomic imaging alone, because metastatic lymph nodes may be no larger than those not affected by disease. ${ }^{79}$ Therefore, there is a role for PET because typically the standardized uptake values (SUV) of metastatic nodes are greater than those not involved. ${ }^{80}$ Finally, the added benefits of PET/MRI with simultaneously obtained and co-registered data for evaluation of the liver in a single examination, potentially using hepatobiliary contrast agents would allow for complete detection and characterization of hepatic metastases which, if present, would affect Mstage. ${ }^{65}$

While clinical staging of cervical cancer has been the long-term accepted solution for local disease, ${ }^{81} \mathrm{PET} / \mathrm{CT}$ has a role in the detection of distant metastases,${ }^{82}$ and there is evolving understanding that pelvic MRI may offer benefit in the preoperative evaluation of tumor stage ${ }^{83}$ Recent reports have shown promise using PET/MRI for the evaluation of newly diagnosed as well as follow-up cervical cancers, integrating morphological and structural information afforded by MRI with the functional information obtained using DWI sequences and FDG uptake from PET $^{84,85}$ (Fig. 9). Similar results have been shown regarding other tumors of gynecologic origin, such as ovarian cancer ${ }^{86,87}$ and endometrial carcinoma. ${ }^{88}$

Another area in which primary tumor evaluation occurs by means of MR imaging is in the prostate ${ }^{89}$ with follow-up after treatment obtained using a combination of biochemical markers and cross-sectional imaging. FDG PET has typically been regarded to have limited utility in low-grade prostate cancer due to overlap of normal glandular FDG uptake with that of pathologic lesions and lack of significant FDG activity in metastases. ${ }^{90,91}$ However, in high grade prostate cancer, such as undifferentiated and neuroendocrine prostate cancer, FDG PET may have utility. ${ }^{92}$ Additionally, there are several non-FDG PET tracers including 18F- and 11C-choline, 18F-FACBC, and 68Ga-prostate specific membrane antigen (PSMA) compounds, which have been shown to have promising results for the evaluation of the primary tumor, local recurrence, and metastatic disease ${ }^{93-95}$ (Fig. 10). Specific studies 
relating to PET/MRI further validate these results,, showing improved detection of primary tumors ${ }^{96}$ and equivalent to rate of detection of metastases when compared with PET/CT. ${ }^{97}$

\section{Lymphoproliferative Disorders}

$\mathrm{PET} / \mathrm{CT}$ is seen by many to be the test of choice in imaging of patients with lymphoma, offering strengths both in detection of disease for staging purposes ${ }^{98}$ and the use of changes in FDG uptake to assess response to therapy. ${ }^{99,100}$ Whole body MRI has also shown value in the imaging of lymphoma, with DWI providing increased contrast to noise and the possibility of quantitative evaluation. ${ }^{101,102}$ It follows that the combination of whole body MRI with DWI and FDG PET would offer the advantages of both technologies while minimizing radiation dose to these patients, many of whom require serial follow-up examinations over a long period of time. To this end, several studies have compared PET/MRI with PET/CT in the evaluation of lymphoma, showing high concordance between staging and comparable SUV max $_{\text {measurements using both modalities in adult }}{ }^{103-105}$ and pediatric patients. ${ }^{106,107}$

\section{Imaging of Infectious and Inflammatory Disorders}

The nonspecific uptake of 18 -FDG as a measure of glycolysis is frequently regarded as a disadvantage in the imaging of oncologic conditions where infectious or inflammatory uptake may mimic neoplastic disease. The use of FDG PET/CT in the evaluation of inflammatory and infectious processes has been shown to be beneficial in a variety of conditions, ${ }^{108}$ and it is hoped that the same will be the case for PET/MRI. Specifically, there are some applications where the fusion of MRI information to PET may be particularly helpful. These include the evaluation of inflammation and infection in the heart and vessels, CNS, liver, GI tract, musculoskeletal system, and as a lower radiation dose alternative to the diagnosis of a cause for fever of unknown origin.

Sarcoidosis is a multisystem inflammatory disorder that may affect a wide range of organ systems, often presenting with vague and difficult to diagnose symptoms. Both PET and MRI are independently useful in the evaluation of cardiac sarcoidosis 109,110 and simultaneously acquired FDG PET images and dedicated cardiac MRI, including multiplanar delayed postgadolinium enhancement, may serve even more beneficial. Similarly, both PET and MRI have specific roles in the imaging of inflammatory and infectious vasculitis and osteomyelitis, and early reports suggest that co-registered anatomic and functional information could prove diagnostically useful. ${ }^{111,112}$ Because many systemic inflammatory and infectious processes affect young patients and these patients may require serial examinations to track disease response to treatment, the decreased radiation dose provided with PET/MRI versus PET/CT is attractive.

\section{Musculoskeletal}

FDG PET/CT is well established for use in patients with multiple myeloma, both sensitive for detection of lytic lesions (CT) and assessment of activity (FDG). ${ }^{113} \mathrm{CT}$ often fails to detect early focal lesions that are not yet lytic. Owing to high soft tissue contrast and better ability to detect marrow lesions, whole body MRI has also been used for the evaluation of multiple myeloma, but suffers from an increased number of false positives compared with 
PET/ $\mathrm{CT}^{114}$; therefore, a combined modality which would feature the sensitivity of whole body MRI with the specificity for active disease of PET is an attractive alternative (Fig. 11). As such, recent studies have shown similar diagnostic accuracy of PET/MRI to PET/CT, ${ }^{115}$ although further investigation to demonstrate a clear benefit is needed.

\section{Pediatrics}

Many of the aforementioned applications of PET/MRI are particularly appealing in children due to the decreased ionizing radiation dose imparted compared with PET/CT, especially in patients with oncologic or chronic inflammatory conditions who may undergo serial followup examinations following therapy. In most settings, between 50 and $80 \%$ of the ionizing radiation dose from an ${ }^{18} \mathrm{~F}$-FDG PET/CT scan can be attributed to the whole body CT examination, with the remaining a result of the radioactive tracer. ${ }^{116}$ Initial papers using $\mathrm{PET} / \mathrm{MRI}$ in place of PET/CT have reported a greater than 50\% decrease in dose as expected, from the removal of the CT component. ${ }^{106,117}$ In addition to the removal of dose from the CT component of the exam, new solid state detectors and improved geometry (longer z-axis coverage and narrower ring diameter) results in sensitivities up to three times higher with new PET/MRI systems than comparable photomultiplier tube PET/CTs. ${ }^{118}$ Therefore, the injected dose of radiotracer can be lowered without sacrificing image quality. It is possible that radiation exposure from pediatric PET/MRI may be decreased by over 90\% compared with the PET/CT studies currently performed.

\section{Future Hurdles to Full PET/MRI Implementation}

Although promising in many aspects, there are several major hurdles that prevent PET/MRI from being more widely adopted. These include the challenges of attenuation correction, detection of processes within the lung, familiarity with the technology, and further evidence that PET/MRI truly offers the hypothesized benefits.

On the two currently available commercial PET/MRI systems, attenuation correction is based on a two-point Dixon acquisition for fat and water segmentation. ${ }^{119}$ In the head, both manufacturers offer an atlas based approach, where Dixon MR images are registered to an atlas that is an average of multiple CT scans and used for attenuation correction. ${ }^{120}$ In the rest of the body, the fat and water fraction images are used for continuous-value attenuation coefficient maps, but this approach does not include separation of air and bone due to the very short $\mathrm{T} 2 *$ of bone $(\mathrm{T} 2 \approx 0.4 \mathrm{~ms})^{121-123}$, thus classifying any intrabody air or bone as soft tissue. Several approaches have been evaluated to differentiate bone from air in the brain, most typically using an MRI sequence with an exceptionally short echo time (UTE ${ }^{24}$ or ZTE ${ }^{25,124,125}$ or a model based approach ${ }^{126}$; however, this topic remains a work in progress with much room remaining for optimization and for translation to whole-body applications (Fig. 12).

Because PET/MRI systems are still relatively rare, there is not widespread knowledge of how these systems may benefit patients. Referring providers may not know the indications for which PET/MRI may be the most helpful. Frequently, referring providers are frustrated when reviewing the numerous sequences and images that are created from a PET/MRI and more comfortable viewing fused images from PET/CT. Interpreting Radiologists and 
Nuclear Medicine physicians may be unfamiliar with the potential artifacts and limitations of the technology, and some Nuclear Medicine physicians may not have the comfort level to interpret the diagnostic MRI portion of a PET/MRI exam. As a result, many centers have each study interpreted by both a Radiologist and a Nuclear Medicine physician; however, this system is time consuming and inefficient. Finally, the quality of examinations would benefit from a group of technologists and imaging staff cross-trained in both Nuclear Medicine and MRI.

Many of the proposed benefits of simultaneous PET and MRI acquisitions rely on novel radiotracers that add additional physiologic information to anatomic MRI images. New tracers such as 68Ga-PSMA-11, 18F-FET, and 18F-fluorodopa need to become FDA approved to become widely available, and approved by the Centers for Medicare \& Medicaid Services (CMS) to be reimbursable. For example, there are three FDA approved radiotracers for amyloid detection in Alzheimer's patients, yet insurance companies will not pay for the cost of the radiotracer in most circumstances. Alzheimer's is potentially a strong application for PET/MRI, but in the absence of reimbursement for amyloid radiotracers, use is limited. There are other common diseases in which PET is not typically reimbursed, including prostate cancer, where both FDG and NaF PET are not historically covered by insurance companies. Some practices have not obtained coverage for 11C-choline and fluciclovine is not CMS approved, limiting the immediate applicability of PET/MRI in prostate cancer patients. Further work needs to be done to update treatment guidelines such as the National Comprehensive Cancer Network (NCCN) to include more PET agents when appropriate, encouraging insurance companies to reimburse for these potentially useful agents.

Finally, as with all new technologies, robust studies demonstrating utility in real-world applications are needed. The existing literature studying PET/MRI typically represent single center case series. Additional data strengthening the indication for PET/MRI would similarly advance the technology. Pooling of multicenter data to demonstrate the utility of PET/MRI will be important, although what the appropriate endpoints and comparators are for these studies are not entirely clear. The majority of studies currently published demonstrate that PET/MRI is superior or equivalent to PET/CT, rather than comparing to PET/CT and MRI performed separately. As a community, we have yet to agree where simultaneous imaging adds value, although there clearly are benefits including decreased dose and convenience that will provide reasons for using PET/MRI.

\section{Conclusions}

As an established technology with advantages in terms of access, cost, speed, and familiarity, PET/CT scanners are unlikely to be replaced by PET/MRI on a one to one basis in the near term. Recognizing the advantages of PET/MRI, which include decreased radiation dose, improved motion correction, and the convenience of a combined exam, it is the role of the imaging community to determine where PET/MRI will add the greatest value. Overall, the future of PET/MRI remains bright but the precise role that PET/ MRI will play remains to be determined. 


\section{References}

1. Lejeune $\mathrm{C}, \mathrm{Al}$ Zahouri $\mathrm{K}$, Woronoff-Lemsi M-C, et al. Use of a decision analysis model to assess the medicoeconomic implications of FDG PET imaging in diagnosing a solitary pulmonary nodule. Eur J Health Econ. 2005; 6:203-214. [PubMed: 15834623]

2. Mansueto M, Grimaldi A, Mangili G, et al. Positron emission tomography/computed tomography introduction in the clinical management of patients with suspected recurrence of ovarian cancer: a cost-effectiveness analysis. Eur J Cancer Care. 2009; 18:612-619.

3. Lejeune C, Bismuth MJ, Conroy T, et al. Use of a decision analysis model to assess the costeffectiveness of 18F-FDG PET in the management of metachronous liver metastases of colorectal cancer. J Nucl Med. 2005; 46:2020-2028. [PubMed: 16330566]

4. Krug B, Crott R, Roch I, et al. Cost-effectiveness analysis of FDG PET-CT in the management of pulmonary metastases from malignant melanoma. Acta Oncol. 2010; 49:192-200. [PubMed: 20059314]

5. Yen R-F, Yen M-F, Hong R-L, Tzen K-Y, Chien C-R, Chen TH-H. The cost-utility analysis of 18fluoro-2-deoxyglucose positron emission tomography in the diagnosis of recurrent nasopharyngeal carcinoma. Acad Radiol. 2009; 16:54-60. [PubMed: 19064212]

6. Sher D, Tishler R, Annino D, Punglia R. Cost-effectiveness of CT and PET-CT for determining the need for adjuvant neck dissection in locally advanced head and neck cancer. Ann Oncol. 2010; 21:1072-1077. [PubMed: 19833820]

7. Sloka JS, Hollett PD, Mathews M. Cost-effectiveness of positron emission tomography in breast cancer. Mol Imaging Biol. 2005; 7:351-360. [PubMed: 16086227]

8. van Loon J, Grutters JP, Wanders R, et al. 18 FDG-PET-CT in the follow-up of non-small cell lung cancer patients after radical radiotherapy with or without chemotherapy: an economic evaluation. Eur J Cancer. 2010; 46:110-119. [PubMed: 19944595]

9. Kee F, Erridge S, Bradbury I, Cairns K. The value of positron emission tomography in patients with non-small cell lung cancer. Eur J Radiol. 2010; 73:50-58. [PubMed: 19084367]

10. Glaudemans AW, de Vries EF, Galli F, Dierckx RA, Slart RH, Signore A. The use of F-FDGPET/CT for diagnosis and treatment monitoring of inflammatory and infectious diseases. Clin Dev Immunol. 2013; 2013:623036. [PubMed: 24027590]

11. Bomanji J, Almuhaideb A, Zumla A. Combined PET and X-ray computed tomography imaging in pulmonary infections and inflammation. Curr Opin Pulm Med. 2011; 17:197-205. [PubMed: 21358408]

12. Jian QY, Doss M, Codreanu I, Zhuang H. PET/CT in patients with sarcoidosis or IgG4 disease. PET Clin. 2012; 7:191-210. [PubMed: 27157236]

13. Schwaiger M, Ziegler S, Nekolla SG. PET/CT: challenge for nuclear cardiology. J Nucl Med. 2005; 46:1664-1678. [PubMed: 16204717]

14. Berti V, Pupi A, Mosconi L. PET/CT in diagnosis of dementia. Ann N Y Acad Sci. 2011; 1228:8192. [PubMed: 21718326]

15. Kim S, Mountz JM. SPECT imaging of epilepsy: an overview and comparison with F-18 FDG PET. Int J Mol Imaging. 2011; 2011:813028. [PubMed: 21785722]

16. Desai A, Bekelis K, Thadani VM, et al. Interictal PET and ictal subtraction SPECT: sensitivity in the detection of seizure foci in patients with medically intractable epilepsy. Epilepsia. 2013; 54:341-350. [PubMed: 23030361]

17. Lucignani G, Paganelli G, Bombardieri E. The use of standardized uptake values for assessing FDG uptake with PET in oncology: a clinical perspective. Nucl Med Commun. 2004; 25:651-656. [PubMed: 15208491]

18. Fraum TJ, Fowler KJ, McConathy J. PET/MRI:: emerging clinical applications in oncology. Acad Radiol. 2016; 23:220-236. [PubMed: 26521689]

19. Herrmann KA, Kohan AA, Gaeta MC, et al. PET/MRI: applications in clinical imaging. Curr Radiol Rep. 2013; 1:161-176.

20. Torigian DA, Zaidi H, Kwee TC, et al. PET/MR imaging: technical aspects and potential clinical applications. Radiology. 2013; 267:26-44. [PubMed: 23525716] 
21. Nensa F, Beiderwellen K, Heusch P, Wetter A. Clinical applications of PET/MRI: current status and future perspectives. Diagn Interv Radiol. 2014; 20:438. [PubMed: 25010371]

22. Purz S, Sabri O, Viehweger A, et al. Potential pediatric applications of PET/MR. J Nucl Med. 2014; 55(Suppl 2):32S-39S. [PubMed: 24762622]

23. Su Y, Rubin BB, McConathy J, et al. Impact of MR-based attenuation correction on neurologic PET studies. J Nucl Med. 2016; 57:913-917. [PubMed: 26823562]

24. Juttukonda MR, Mersereau BG, Chen Y, et al. MR-based attenuation correction for PET/MRI neurological studies with continuous-valued attenuation coefficients for bone through a conversion from R2* to CT-Hounsfield units. Neuroimage. 2015; 112:160-168. [PubMed: 25776213]

25. Sekine T, Ter Voert EE, Warnock G, et al. Clinical evaluation of zero-echo-time attenuation correction for brain 18F-FDG PET/MRI: comparison with atlas attenuation correction. J Nucl Med. 2016; 57:1927-1932. [PubMed: 27339875]

26. Sunderland JJ, Christian PE. Quantitative PET/CT scanner performance characterization based upon the society of nuclear medicine and molecular imaging clinical trials network oncology clinical simulator phantom. J Nucl Med. 2015; 56:145-152. [PubMed: 25525180]

27. Fahey FH, Kinahan PE, Doot RK, Kocak M, Thurston H, Poussaint TY. Variability in PET quantitation within a multicenter consortium. Med Phys. 2010; 37:3660-3666. [PubMed: 20831073]

28. Tropp J. Image brightening in samples of high dielectric constant. J Magn Reson. 2004; 167:1224. [PubMed: 14987593]

29. Ziegler S, Braun H, Ritt P, Hocke C, Kuwert T, Quick HH. Systematic evaluation of phantom fluids for simultaneous PET/MR hybrid imaging. J Nucl Med. 2013; 54:1464-1471. [PubMed: 23792278]

30. Iagaru A, Mittra E, Minamimoto R, et al. Simultaneous whole-body time-of-flight 18F-FDG PET/ MRI: a pilot study comparing $\mathrm{SUV}_{\max }$ with PET/CT and assessment of MR image quality. Clin Nucl Med. 2015; 40:1-8. [PubMed: 25489952]

31. Mehranian A, Zaidi H. Impact of time-of-flight PET on quantification errors in MR imaging-based attenuation correction. J Nucl Med. 2015; 56:635-641. [PubMed: 25745090]

32. Grueneisen J, Sawicki LM, Schaarschmidt BM, et al. Evaluation of a fast protocol for staging lymphoma patients with integrated PET/MRI. PLoS One. 2016; 11:e0157880. [PubMed: 27327617]

33. Grueneisen J, Schaarschmidt BM, Heubner M, et al. Implementation of FAST-PET/MRI for wholebody staging of female patients with recurrent pelvic malignancies: a comparison to PET/CT. Eur J Radiol. 2015; 84:2097-2102. [PubMed: 26321491]

34. Schaarschmidt BM, Grueneisen J, Heusch P, et al. Oncological whole-body staging in integrated 18 F-FDG PET/MR: value of different MR sequences for simultaneous PET and MR reading. Eur J Radiol. 2015; 84:1285-1292. [PubMed: 25975895]

35. Huellner MW, de Galiza Barbosa F, Husmann L, et al. TNM staging of non-small cell lung cancer: comparison of PET/MR and PET/CT. J Nucl Med. 2016; 57:21-26. [PubMed: 26471696]

36. Rakheja R, Chandarana H, DeMello L, et al. Correlation between standardized uptake value and apparent diffusion coefficient of neoplastic lesions evaluated with whole-body simultaneous hybrid PET/MRI. AJR Am J Roentgenol. 2013; 201:1115-1119. [PubMed: 24147485]

37. Salamon N, Kung J, Shaw S, et al. FDG-PET/MRI coregistration improves detection of cortical dysplasia in patients with epilepsy. Neurology. 2008; 71:1594-1601. [PubMed: 19001249]

38. Chandra PS, Salamon N, Huang J, et al. FDG-PET/MRI Coregistration and diffusion-tensor imaging distinguish epileptogenic tubers and cortex in patients with tuberous sclerosis complex: a preliminary report. Epilepsia. 2006; 47:1543-1549. [PubMed: 16981871]

39. Carne R, O'Brien T, Kilpatrick C, et al. MRI-negative PET-positive temporal lobe epilepsy: a distinct surgically remediable syndrome. Brain. 2004; 127:2276-2285. [PubMed: 15282217]

40. Petrecca K, Guiot MC, Panet-Raymond V, Souhami L. Failure pattern following complete resection plus radiotherapy and temozolomide is at the resection margin in patients with glioblastoma. J Neurooncol. 2013; 111:19-23. [PubMed: 23054563]

41. Chamberlain MC. Radiographic patterns of relapse in glioblastoma. J Neurooncol. 2011; 101:319323. [PubMed: 21052776] 
42. McDonald MW, Shu HK, Curran WJ Jr, Crocker IR. Pattern of failure after limited margin radiotherapy and temozolomide for glioblastoma. Int J Radiat Oncol Biol Phys. 2011; 79:130-136. [PubMed: 20399036]

43. Valk PE, Dillon WP. Radiation injury of the brain. AJNR Am J Neuroradiol. 1991; 12:45-62. [PubMed: 7502957]

44. Glantz MJ, Hoffman JM, Coleman RE, et al. Identification of early recurrence of primary central nervous system tumors by $[18 \mathrm{~F}]$ fluorodeoxyglucose positron emission tomography. Ann Neurol. 1991; 29:347-355. [PubMed: 1929205]

45. Spence AM, Muzi M, Link JM, et al. NCI-sponsored trial for the evaluation of safety and preliminary efficacy of $3^{\prime}$-deoxy- $3^{\prime}$-[18F]fluorothymidine (FLT) as a marker of proliferation in patients with recurrent gliomas: preliminary efficacy studies. Mol Imaging Biol. 2009; 11:343355. [PubMed: 19326172]

46. Hirata K, Terasaka S, Shiga T, et al. (1)(8)F-Fluoromisonidazole positron emission tomography may differentiate glioblastoma multiforme from less malignant gliomas. Eur J Nucl Med Mol Imaging. 2012; 39:760-770. [PubMed: 22307533]

47. Pirotte BJ, Levivier M, Goldman S, et al. Positron emission tomography-guided volumetric resection of supratentorial high-grade gliomas: a survival analysis in 66 consecutive patients. Neurosurgery. 2009; 64:471-481. discussion 481. [PubMed: 19240609]

48. Galldiks N, Rapp M, Stoffels G, et al. Response assessment of bevaci-zumab in patients with recurrent malignant glioma using [18F]Fluoroethyl-L-tyrosine PET in comparison to MRI. Eur J Nucl Med Mol Imaging. 2013; 40:22-33. [PubMed: 23053325]

49. Chen W, Silverman DH, Delaloye S, et al. 18F-FDOPA PET imaging of brain tumors: comparison study with 18F-FDG PET and evaluation of diagnostic accuracy. J Nucl Med. 2006; 47:904-911. [PubMed: 16741298]

50. Platzek I, Beuthien-Baumann B, Schneider M, et al. PET/MRI in head and neck cancer: initial experience. Eur J Nucl Med Mol Imaging. 2013; 40:6-11. [PubMed: 23053322]

51. Lee SJ, Seo HJ, Cheon GJ, et al. Usefulness of integrated PET/MRI in head and neck cancer: a preliminary study. Nucl Med Mol Imaging. 2014; 48:98-105. [PubMed: 24900149]

52. Schaarschmidt BM, Heusch P, Buchbender C, et al. Locoregional tumour evaluation of squamous cell carcinoma in the head and neck area: a comparison between MRI, PET/CT and integrated PET/MRI. Eur J Nucl Med Mol Imaging. 2016; 43:92-102. [PubMed: 26243264]

53. Surov A, Stumpp P, Meyer HJ, et al. Simultaneous 18 F-FDG-PET/ MRI: associations between diffusion, glucose metabolism and histopathological parameters in patients with head and neck squamous cell carcinoma. Oral Oncol. 2016; 58:14-20. [PubMed: 27311397]

54. Ruhlmann V, Ruhlmann M, Bellendorf A, et al. Hybrid imaging for detection of carcinoma of unknown primary: a preliminary comparison trial of whole-body PET/MRI versus PET/CT. Eur J Radiol. 2016; 85:1941-1947. [PubMed: 27776644]

55. Heusch P, Buchbender C, Kohler J, et al. Correlation of the apparent diffusion coefficient (ADC) with the standardized uptake value (SUV) in hybrid 18F-FDG PET/MRI in non-small cell lung cancer (NSCLC) lesions: initial results. RoFo. 2013; 185:1056-1062. [PubMed: 23860802]

56. Schmidt H, Brendle C, Schraml C, et al. Correlation of simultaneously acquired diffusion-weighted imaging and 2-deoxy-[18F] fluoro-2-D-glucose positron emission tomography of pulmonary lesions in a dedicated whole-body magnetic resonance/positron emission tomography system. Invest Radiol. 2013; 48:247-255. [PubMed: 23519008]

57. Schaarschmidt BM, Grueneisen J, Metzenmacher M, et al. Thoracic staging with 18F-FDG $\mathrm{PET} / \mathrm{MR}$ in non-small cell lung cancer - does it change therapeutic decisions in comparison to 18F-FDG PET/CT? Eur Radiol. 2017; 27:681-688. [PubMed: 27180186]

58. Ohno Y, Koyama H, Yoshikawa T, et al. Three-way comparison of whole-body MR, coregistered whole-body FDG PET/MR, and integrated whole-body FDG PET/CT imaging: TNM and stage assessment capability for non-small cell lung cancer patients. Radiology. 2015; 275:849-861. [PubMed: 25584709]

59. Heusch P, Buchbender C, Kohler J, et al. Thoracic staging in lung cancer: prospective comparison of 18F-FDG PET/MR imaging and 18F-FDG PET/CT. J Nucl Med : official publication, Soc Nucl Med. 2014; 55:373-378. 
60. Sawicki LM, Grueneisen J, Buchbender C, et al. Evaluation of the outcome of lung nodules missed on 18F-FDG PET/MRI compared with 18F-FDG PET/CT in patients with known malignancies. J Nucl Med. 2016; 57:15-20. [PubMed: 26514173]

61. Sawicki LM, Grueneisen J, Buchbender C, et al. Comparative performance of 18F-FDG PET/MRI and 18F-FDG PET/CT in detection and characterization of pulmonary lesions in 121 oncologic patients. J Nucl Med. 2016; 57:582-586. [PubMed: 26742715]

62. Chandarana H, Heacock L, Rakheja R, et al. Pulmonary nodules in patients with primary malignancy: comparison of hybrid PET/MR and PET/CT imaging. Radiology. 2013; 268:874-881. [PubMed: 23737537]

63. Burris NS, Johnson KM, Larson PE, et al. Detection of small pulmonary nodules with ultrashort echo time sequences in oncology patients by using a PET/MR system. Radiology. 2016; 278:239246. [PubMed: 26133050]

64. Clark TJ, Flood TF, Maximin ST, Sachs PB. Lung CT screening reporting and data system speed and accuracy are increased with the use of a semiautomated computer application. J Am Coll Radiol. 2015; 12(Pt A):1301-1306. [PubMed: 26507823]

65. Kang B, Lee JM, Song YS, et al. Added value of integrated whole-body PET/MRI for evaluation of colorectal cancer: comparison with contrast-enhanced MDCT. AJR Am J Roentgenol. 2016; 206:W10-W20. [PubMed: 26700358]

66. Patel S, Cheek S, Osman H, Jeyarajah DR. MRI with gadoxetate disodium for colorectal liver metastasis: is it the new "imaging modality of choice"? J Gastrointest. 2014; 18:2130-2135.

67. Cheung TT, Ho CL, Lo CM, et al. 11C-acetate and 18F-FDG PET/CT for clinical staging and selection of patients with hepatocellular carcinoma for liver transplantation on the basis of Milan criteria: surgeon's perspective. J Nucl Med. 2013; 54:192-200. [PubMed: 23321459]

68. Chen S, Cheung W, Leung WT, et al. Response prediction in HCC patients treated with 90Y glass microspheres based on metabolic parameters: post-radioembolization 90Y PET/CT tumor dose and pretreatment 11C-acetate \& 18F-FDG PET/CT metobolic grading. J Nucl Med. 2016; 57(Suppl 2):296-296.

69. Lee J, Bijan B. Comparison of different functional imaging modalities including FDG PET/CT and DWI-MRI with respect to their value in TNM staging of cholangiocarcinoma. J Nucl Med. 2016; 57(Suppl 2):1291-1291.

70. Poeppel TD, Binse I, Petersenn S, et al. 68Ga-DOTATOC versus 68Ga-DOTATATE PET/CT in functional imaging of neuroendocrine tumors. J Nucl Med. 2011; 52:1864-1870. [PubMed: 22072704]

71. Lau SK, Schembri G, Hain S, Roach P. Value of Gallium-68 Dotatate PET Scan in staging patients with appendiceal carcinoid tumour: a case series. J Nucl Med. 2015; 56(Suppl 3):1660.

72. Haug A, Angele M, Auernhammer C, et al. 68Ga-DOTATATE PET/CT in the pre-surgical staging of ileal and pancreatic neuroendocrine tumors: correlation with histopathology and impact on surgical management. J Nucl Med. 2013; 54(Suppl 2):108.

73. Smith N, Brown G. Preoperative staging of rectal cancer. Acta Oncol. 2008; 47:20-31. [PubMed: 17957502]

74. Barbaro B, Vitale R, Leccisotti L, et al. Restaging locally advanced rectal cancer with MR imaging after chemoradiation therapy. Radiographics. 2010; 30:699-716. [PubMed: 20462989]

75. Patel UB, Taylor F, Blomqvist L, et al. Magnetic resonance imaging-detected tumor response for locally advanced rectal cancer predicts survival outcomes: MERCURY experience. J Clin Oncol. 2011; 29:3753-3760. [PubMed: 21876084]

76. Guillem JG, Moore HG, Akhurst T, et al. Sequential preoperative fluorodeoxyglucose-positron emission tomography assessment of response to preoperative chemoradiation: a means for determining longterm outcomes of rectal cancer. J Am Coll Surg. 2004; 199:1-7. [PubMed: 15217621]

77. Kalff V, Duong C, Drummond EG, Matthews JP, Hicks RJ. Findings on 18F-FDG PET scans after neoadjuvant chemoradiation provides prognostic stratification in patients with locally advanced rectal carcinoma subsequently treated by radical surgery. J Nucl Med. 2006; 47:14-22. [PubMed: 16391182] 
78. O’Neill BD, Brown G, Heald RJ, Cunningham D, Tait DM. Non-operative treatment after neoadjuvant chemoradiotherapy for rectal cancer. Lancet Oncol. 2007; 8:625-633. [PubMed: 17613424]

79. Dworak O. Morphology of lymph nodes in the resected rectum of patients with rectal carcinoma. Pathol Res Pract. 1991; 187:1020-1024. [PubMed: 1792183]

80. Kijima S, Sasaki T, Nagata K, Utano K, Lefor AT, Sugimoto H. Preoperative evaluation of colorectal cancer using CT colonography, MRI, and PET/CT. World J Gastroenterol. 2014; 20:16964-16975. [PubMed: 25493009]

81. Quinn MA, Benedet JL, Odicino F, et al. Carcinoma of the cervix uteri, FIGO 26th Annual Report on the Results of Treatment in Gynecological Cancer. Int J Gynaecol Obstet. 2006; 95(Suppl 1):S43-S103. [PubMed: 17161167]

82. Havrilesky LJ, Kulasingam SL, Matchar DB, Myers ER. FDG-PET for management of cervical and ovarian cancer. Gynecol Oncol. 2005; 97:183-191. [PubMed: 15790456]

83. Bourgioti C, Chatoupis K, Rodolakis A, et al. Incremental prognostic value of MRI in the staging of early cervical cancer: a prospective study and review of the literature. Clin Imaging. 2016; 40:72-78. [PubMed: 26459788]

84. Grueneisen J, Schaarschmidt BM, Heubner M, et al. Integrated PET/MRI for whole-body staging of patients with primary cervical cancer: preliminary results. Eur J Nucl Med Mol Imaging. 2015; 42:1814-1824. [PubMed: 26199113]

85. Grueneisen J, Beiderwellen K, Heusch P, et al. Correlation of standardized uptake value and apparent diffusion coefficient in integrated whole-body PET/MRI of primary and recurrent cervical cancer. PLoS One. 2014; 9:e96751. [PubMed: 24804676]

86. Beiderwellen K, Grueneisen J, Ruhlmann V, et al. [(18)F]FDG PET/MRI vs PET/CT for wholebody staging in patients with recurrent malignancies of the female pelvis: initial results. Eur J Nucl Med Mol Imaging. 2015; 42:56-65. [PubMed: 25223420]

87. Nakajo K, Tatsumi M, Inoue A, et al. Diagnostic performance of fluorodeoxyglucose positron emission tomography/magnetic resonance imaging fusion images of gynecological malignant tumors: comparison with positron emission tomography/computed tomography. Jpn J Radiol. 2010; 28:95-100. [PubMed: 20182843]

88. Shih IL, Yen RF, Chen CA, et al. Standardized uptake value and apparent diffusion coefficient of endometrial cancer evaluated with integrated whole-body PET/MR: correlation with pathological prognostic factors. J Magn Reson Imaging. 2015; 42:1723-1732. [PubMed: 25919115]

89. Vargas HA, Akin O, Franiel T, et al. Diffusion-weighted endorectal MR imaging at 3 T for prostate cancer: tumor detection and assessment of aggressiveness. Radiology. 2011; 259:775-784. [PubMed: 21436085]

90. Minamimoto R, Uemura H, Sano F, et al. The potential of FDG-PET/CT for detecting prostate cancer in patients with an elevated serum PSA level. Ann Nucl Med. 2011; 25:21-27. [PubMed: 20931305]

91. Salminen E, Hogg A, Binns D, Frydenberg M, Hicks R. Investigations with FDG-PET scanning in prostate cancer show limited value for clinical practice. Acta Oncol. 2002; 41:425-429. [PubMed: 12442917]

92. Jadvar H. Imaging evaluation of prostate cancer with 18F-fluorodeoxyglucose PET/CT: utility and limitations. Eur J Nucl Med Mol Imaging. 2013; 40:5-10.

93. Watanabe H, Kanematsu M, Kondo H, et al. Preoperative detection of prostate cancer: a comparison with 11C-choline PET, 18F-fluorodeoxyglucose PET and MR imaging. J Magn Reson Imaging. 2010; 31:1151-1156. [PubMed: 20432351]

94. Afshar-Oromieh A, Malcher A, Eder M, et al. PET imaging with a [68Ga] gallium-labelled PSMA ligand for the diagnosis of prostate cancer: biodistribution in humans and first evaluation of tumour lesions. Eur J Nucl Med Mol Imaging. 2013; 40:486-495. [PubMed: 23179945]

95. Afshar-Oromieh A, Zechmann CM, Malcher A, et al. Comparison of PET imaging with a 68Galabelled PSMA ligand and 18F-choline-based PET/CT for the diagnosis of recurrent prostate cancer. Eur J Nucl Med Mol Imaging. 2014; 41:11-20. [PubMed: 24072344]

96. Eiber M, Weirich G, Holzapfel K, et al. Simultaneous 68Ga-PSMA HBED-CC PET/MRI improves the localization of primary prostate cancer. Eur Urol. 2016; 70:829-836. [PubMed: 26795686] 
97. Freitag MT, Radtke JP, Hadaschik BA, et al. Comparison of hybrid 68Ga-PSMA PET/MRI and $68 \mathrm{Ga}-\mathrm{PSMA}$ PET/CT in the evaluation of lymph node and bone metastases of prostate cancer. Eur J Nucl Med Mol Imaging. 2016; 43:70-83. [PubMed: 26508290]

98. Cronin CG, Swords R, Truong MT, et al. Clinical utility of PET/CT in lymphoma. AJR Am J Roentgenol. 2010; 194:W91-W103. [PubMed: 20028897]

99. Juweid ME, Stroobants S, Hoekstra OS, et al. Use of positron emission tomography for response assessment of lymphoma: consensus of the Imaging Subcommittee of International Harmonization Project in Lymphoma. J Clin Oncol. 2007; 25:571-578. [PubMed: 17242397]

100. Hutchings M, Barrington SF. PET/CT for therapy response assessment in lymphoma. J Nucl Med. 2009; 50(Suppl 1):21S-30S. [PubMed: 19380407]

101. Kwee TC, Vermoolen MA, Akkerman EA, et al. Whole-body MRI, including diffusion-weighted imaging, for staging lymphoma: comparison with CT in a prospective multicenter study. J Magn Reson Imaging. 2014; 40:26-36. [PubMed: 24307538]

102. van Ufford HMQ, Kwee TC, Beek FJ, et al. Newly diagnosed lymphoma: initial results with whole-body T1-weighted, STIR, and diffusion-weighted MRI compared with 18F-FDG PET/CT. AJR Am J Roentgenol. 2011; 196:662-669. [PubMed: 21343511]

103. Heacock L, Weissbrot J, Raad R, et al. PET/MRI for the evaluation of patients with lymphoma: initial observations. AJR Am J Roentgenol. 2015; 204:842-848. [PubMed: 25794075]

104. Afaq A, Fraioli F, Sidhu H, et al. Comparison of PET/MRI with PET/ CT in the evaluation of disease status in lymphoma. Clin Nucl Med. 2017; 42:e1-e7. [PubMed: 27607161]

105. Atkinson W, Catana C, Abramson JS, et al. Hybrid FDG-PET/MR compared to FDG-PET/CT in adult lymphoma patients. Abdom Radiol (NY). 2016; 41:1338-1348. [PubMed: 27315095]

106. Sher AC, Seghers V, Paldino MJ, et al. Assessment of sequential PET/MRI in comparison with PET/CT of pediatric lymphoma: a prospective study. AJR Am J Roentgenol. 2016; 206:623-631. [PubMed: 26901021]

107. Ponisio MR, McConathy J, Laforest R, Khanna G. Evaluation of diagnostic performance of whole-body simultaneous PET/MRI in pediatric lymphoma. Pediatr Radiol. 2016; 46:1258-1268. [PubMed: 27003132]

108. Vaidyanathan S, Patel CN, Scarsbrook AF, Chowdhury FU. FDG PET/ CT in infection and inflammation-current and emerging clinical applications. Clin Radiol. 2015; 70:787-800. [PubMed: 25917543]

109. Zandieh S, Bernt R, Mirzaei S, Haller J, Hergan K. Image fusion between 18F-FDG PET and MRI in cardiac sarcoidosis: a case series. J Nucl Cardiol. 2016:1-7.

110. Schatka I, Bengel FM. Advanced imaging of cardiac sarcoidosis. J Nucl Med. 2014; 55:99-106. [PubMed: 24232870]

111. Matthews R, Brunetti V, Martin B, Franceschi D. PET-MRI in diagnosing pedal osteomyelitis in diabetic patients. J Nucl Med. 2015; 56(Suppl 3):307.

112. Einspieler I, Thürmel K, Eiber M, Pyka T, Essler M. Imaging large vessel vasculitis with fully integrated PET/MR: a pilot study. J Nucl Med. 2014; 55(Suppl 1):185.

113. Zamagni E, Cavo M. The role of imaging techniques in the management of multiple myeloma. $\mathrm{Br}$ J Haematol. 2012; 159:499-513. [PubMed: 22881361]

114. Derlin T, Peldschus K, Münster S, et al. Comparative diagnostic performance of 18F-FDG PET/CT versus whole-body MRI for determination of remission status in multiple myeloma after stem cell transplantation. Eur Radiol. 2013; 23:570-578. [PubMed: 22843058]

115. Sachpekidis C, Hillengass J, Goldschmidt H, et al. Comparison of (18)F-FDG PET/CT and PET/MRI in patients with multiple myeloma. Am J Nucl Med Mol Imaging. 2015; 5:469-478. [PubMed: 26550538]

116. Huang B, Law MW, Khong PL. Whole-body PET/CT scanning: estimation of radiation dose and cancer risk. Radiology. 2009; 251:166-174. [PubMed: 19251940]

117. Gatidis S, Schmidt H, Gücke B, et al. Comprehensive oncologic imaging in infants and preschool children with substantially reduced radiation exposure using combined simultaneous $18 \mathrm{~F}$ fluorodeoxyglucose positron emission tomography/magnetic resonance imaging: a direct comparison to $18 \mathrm{~F}$-fluorodeoxyglucose positron emission tomography/computed tomography. Invest Radiol. 2016; 51:7-14. [PubMed: 26309185] 
118. Levin CS, Maramraju SH, Khalighi MM, Deller TW, Delso G, Jansen F. Design features and mutual compatibility studies of the time-of-flight PET capable GE SIGNA PET/MR system. IEEE Trans Med Imaging. 2016; 35:1907-1914. [PubMed: 26978664]

119. Wollenweber S, Ambwani S, Lonn A, et al. Comparison of 4-class and continuous fat/water methods for whole-body, MR-based PET attenuation correction. IEEE Trans Nucl Sci. 2013; 60:3391-3398.

120. Sekine T, Buck A, Delso G, et al. Evaluation of atlas-based attenuation correction for integrated PET/MR in human brain: application of a head atlas and comparison to true CT-based attenuation correction. J Nucl Med. 2016; 57:215-220. [PubMed: 26493207]

121. Horch RA, Nyman JS, Gochberg DF, Dortch RD, Does MD. Characterization of 1H NMR signal in human cortical bone for magnetic resonance imaging. Magn Reson Med. 2010; 64:680-687. [PubMed: 20806375]

122. Du J, Carl M, Bydder M, Takahashi A, Chung CB, Bydder GM. Qualitative and quantitative ultrashort echo time (UTE) imaging of cortical bone. J Magn Reson. 2010; 207:304-311. [PubMed: 20980179]

123. Krug R, Larson PE, Wang C, et al. Ultrashort echo time MRI of cortical bone at 7 tesla field strength: a feasibility study. J Magn Reson Imaging. 2011; 34:691-695. [PubMed: 21769960]

124. Wiesinger F, Sacolick LI, Menini A, et al. Zero TE MR bone imaging in the head. Magn Reson Med. 2016; 75:107-114. [PubMed: 25639956]

125. Leynes AP, Yang J, Shanbhag DD, et al. Hybrid ZTE/Dixon MR-based attenuation correction for quantitative uptake estimation of pelvic lesions in PET/MRI. Med Phys. 2017; doi: 10.1002/mp. 12122

126. Paulus DH, Quick HH, Geppert C, et al. Whole-body PET/MR imaging: quantitative evaluation of a novel model-based MR attenuation correction method including bone. J Nucl Med. 2015; 56:1061-1066. [PubMed: 26025957] 

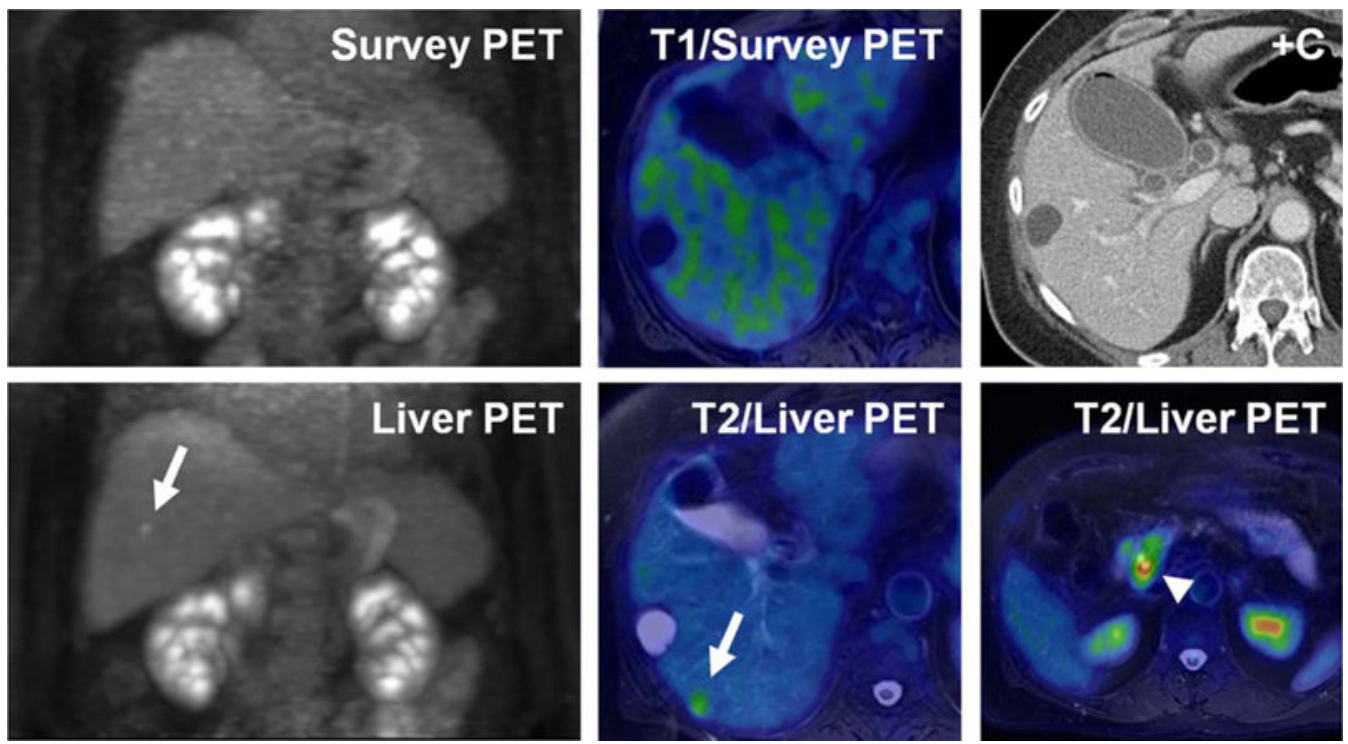

FIGURE 1.

A 67-year-old woman with known pancreas head mass (arrowhead) referred for PET/MRI to evaluate for metastatic disease. Whole body survey PET images, acquired over 2 min per table position, as well as contrast enhanced CT and MR images did not demonstrate any suspicious lesions within the liver. Dedicated PET acquisition in the liver bed position over 10 min clearly shows an FDG avid focus in the posterior hepatic lobe (arrows). This finding was confirmed to represent metastatic disease at the time of surgery. 

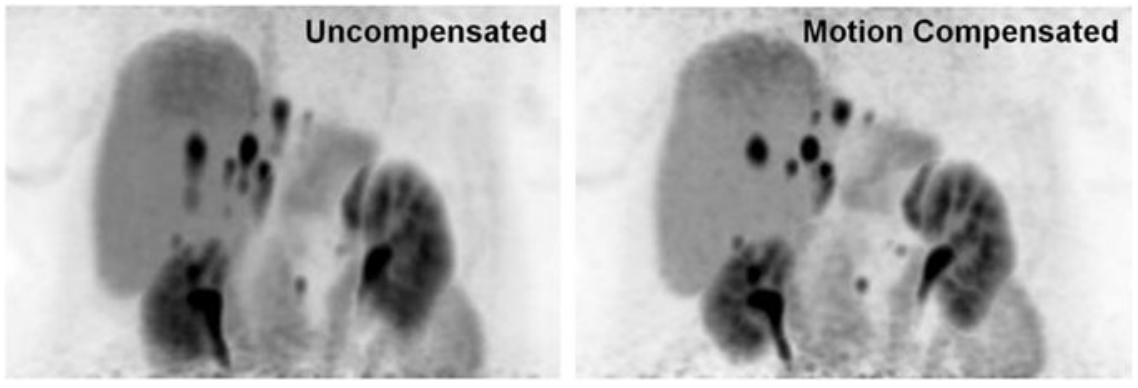

FIGURE 2.

MIP 68-GA DOTA-TOC PET images from a 71-year-old man. Uncompensated images (left) suffer from blurring along the Z-axis due to respiratory motion. Motion compensated (right) images generated by filtering temporal PET data according to MR respiratory gating show decreased respiratory artifact, improving image quality and accuracy of SUV observations. 

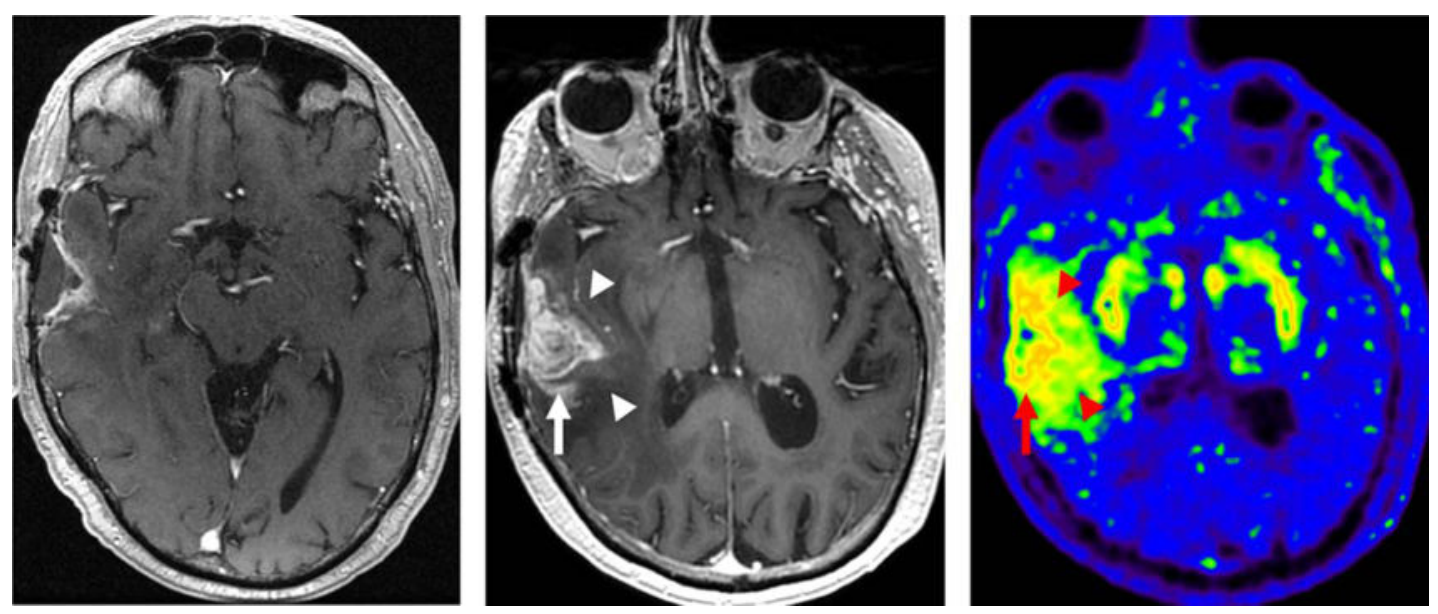

FIGURE 3.

A 69-year-old man with glioblastoma treated with surgical resection, chemoradiotherapy, and adjuvant temozolomide. Postgadolinium enhanced MRI at 6 months following completion of adjuvant therapy (left) and follow-up postgadolinium enhanced MRI at 9 months following completion of radiotherapy (center) demonstrate interval progression of enhancing and nonenhancing tumor. 18F-DOPA PET performed as part of PET/MRI at 9 months following completion of radiotherapy (right) demonstrates radiotracer uptake in regions of enhancing (arrow) and nonenhancing (arrowheads) tumor. Note physiologic putamenal uptake bilaterally. 

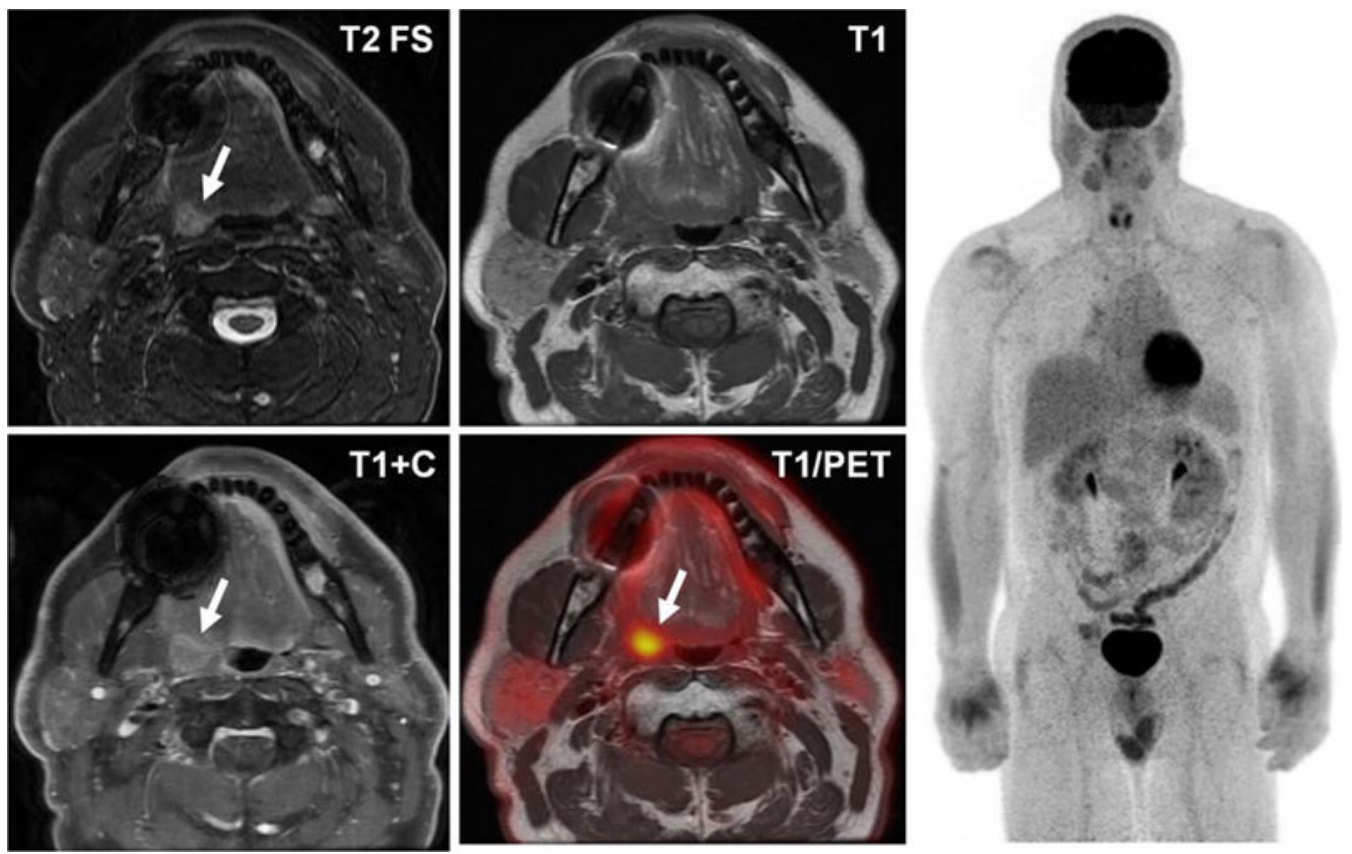

FIGURE 4.

FDG PET/MRI performed to further evaluate a tonsillar mass in a 58-year-old man. Note presence of a T2 hyperintense, enhancing lesion in the right tonsillar region (arrows), with corresponding FDG avidity. There was no FDG or MRI evidence of distant disease on whole body imaging. 

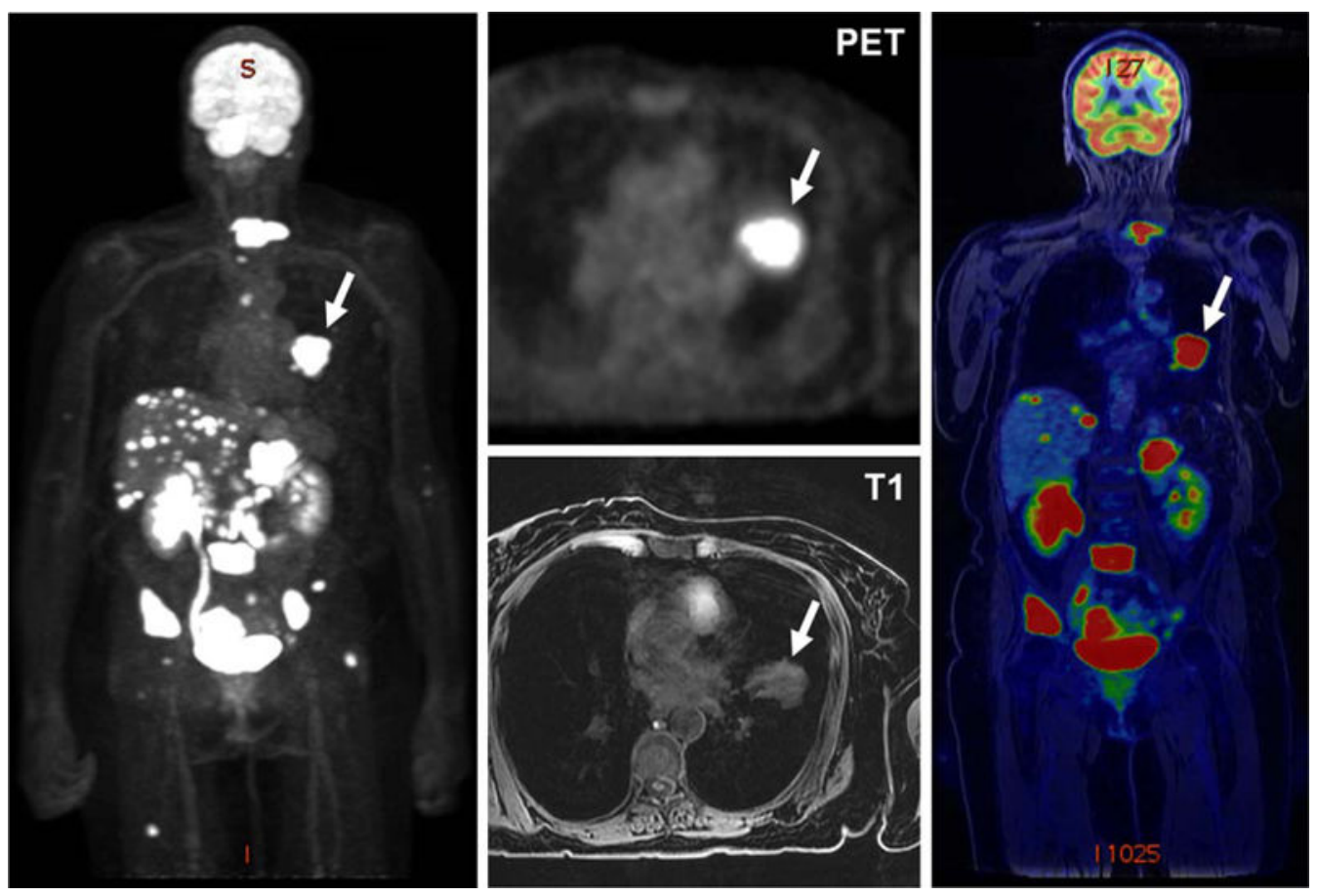

FIGURE 5.

PET/MRI performed for workup of a left lung mass noted in a 65-year-old woman demonstrates a large hypermetabolic left lung tumor (arrows) and extensive hepatic, adrenal, osseous, and peritoneal metastases. Subsequent biopsy of a liver mass confirmed metastatic adenocarcinoma of the lung. 

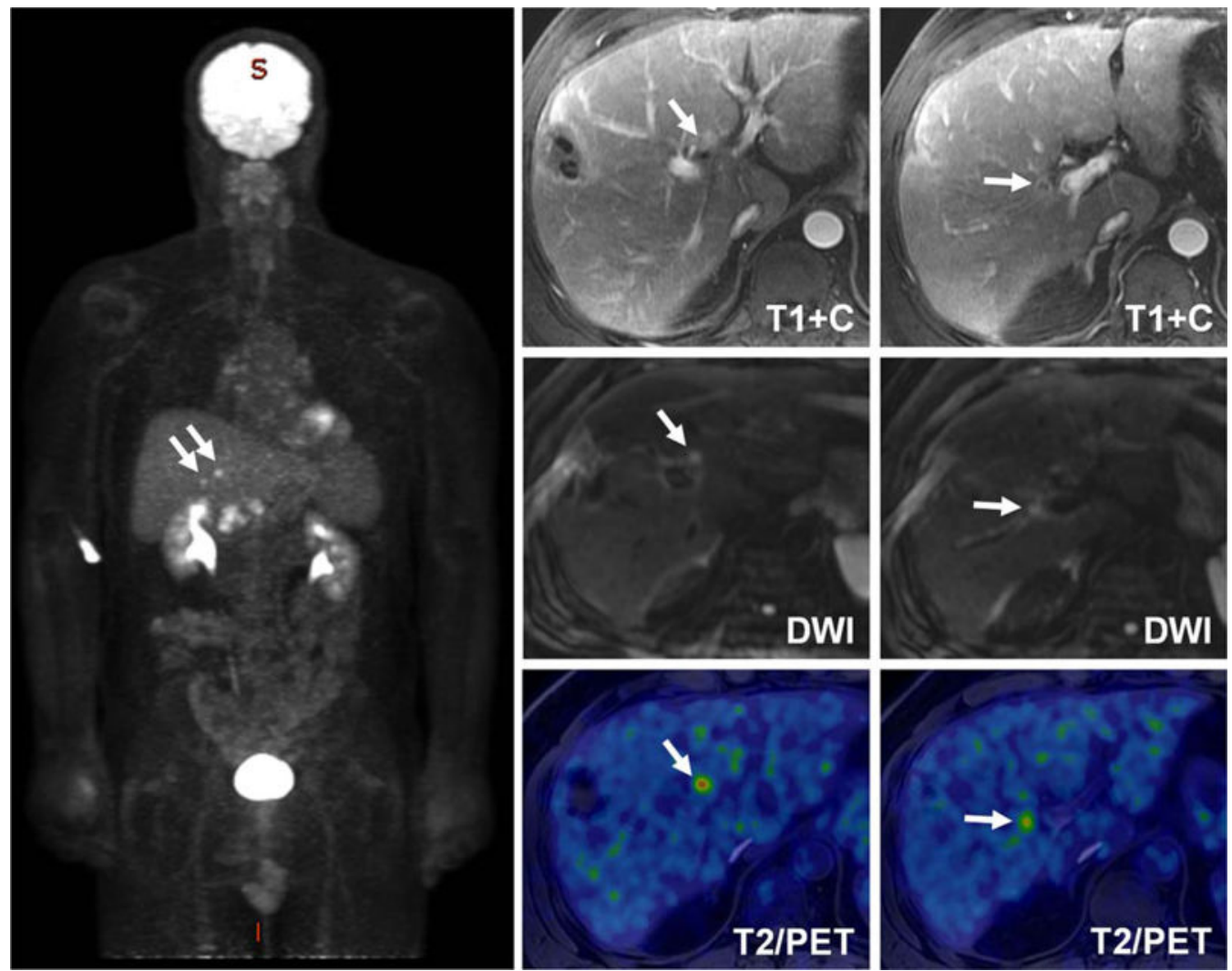

FIGURE 6.

A 52-year-old man with sigmoid colon cancer metastatic to the liver, status post segment $\mathrm{V}$ right partial hepatectomy with intra-operative ablation of a tumor in segment VIII. PET/MRI images following the procedure show two areas (arrows) of enhancement (top) and restricted diffusion (middle). These findings are quite subtle and could be interpreted as nonspecific, however, the addition of fusion FDG PET images (bottom) clearly demonstrates hypermetabolism, suggesting additional undiagnosed tumor burden. 

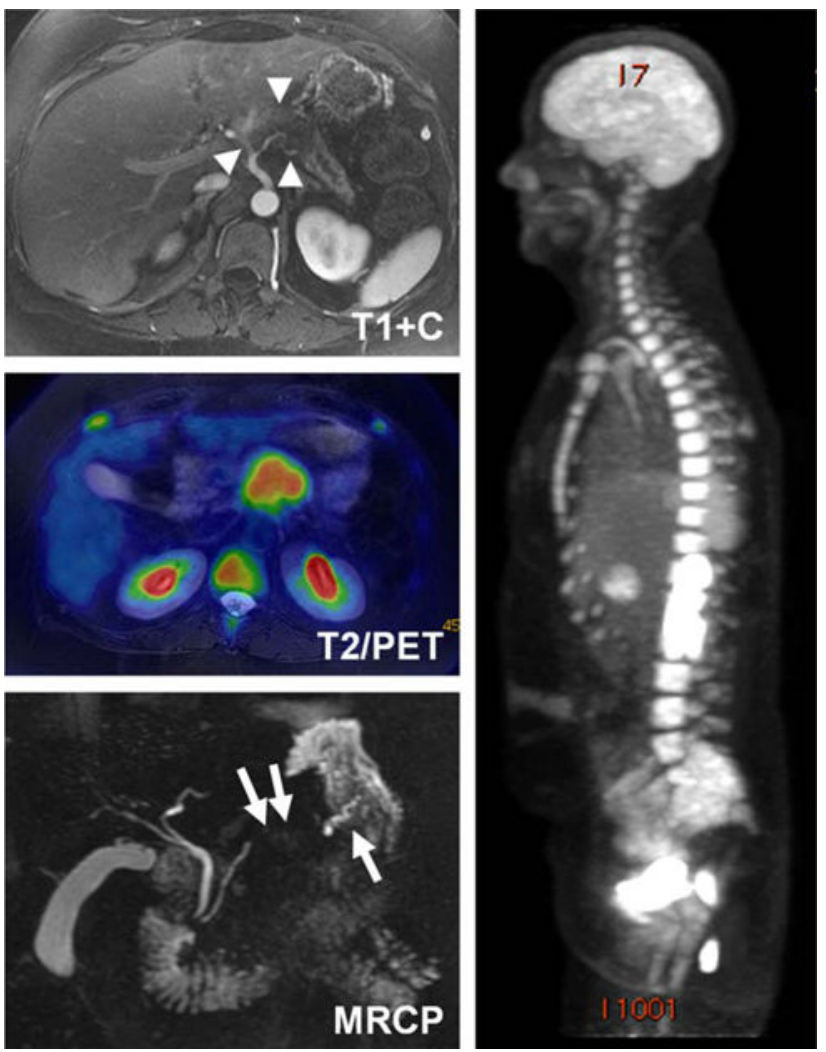

FIGURE 7.

PET/MRI images obtained in a 53-year-old woman with biopsy proven adenocarcinoma of the pancreatic body. Postcontrast T1-weighted images show a hypoenhancing tumor with abutment of the celiac axis and common hepatic arteries as well as encasement and narrowing of the splenic artery (arrowheads, top), while fused PET/T2 weighted and MIP PET images show FDG uptake attributable to the tumor (center, right). Concurrently performed MRCP demonstrates focal obliteration of the pancreatic duct in the region of the tumor, with upstream dilation (arrows, bottom). 

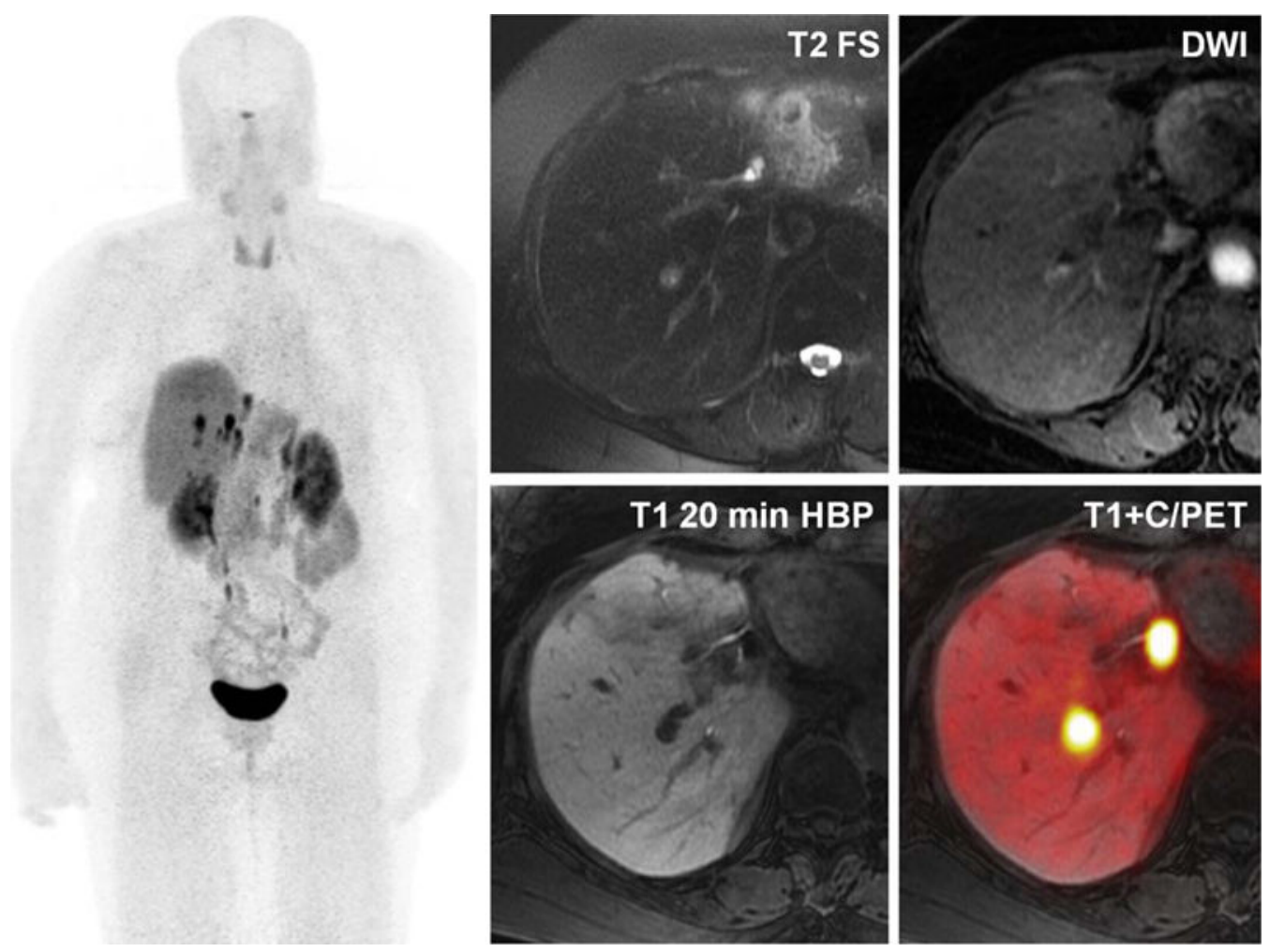

FIGURE 8.

A 71-year-old man with metastatic neuroendocrine tumor. PET/MRI exam performed with 68-Ga DOTA-TOC demonstrates intermediate T2 hyperintense lesions with mild restricted diffusion and lack of hepatocyte contrast uptake on 20-min postinjection T1-weighted images. Fused contrast enhanced/PET images demonstrate marked uptake of DOTA-TOC somatostatin analogue at the sites of MRI abnormality, compatible with metastatic disease. Note blurring of hepatic metastases on whole body MIP images, a result of uncorrected respiratory motion. 

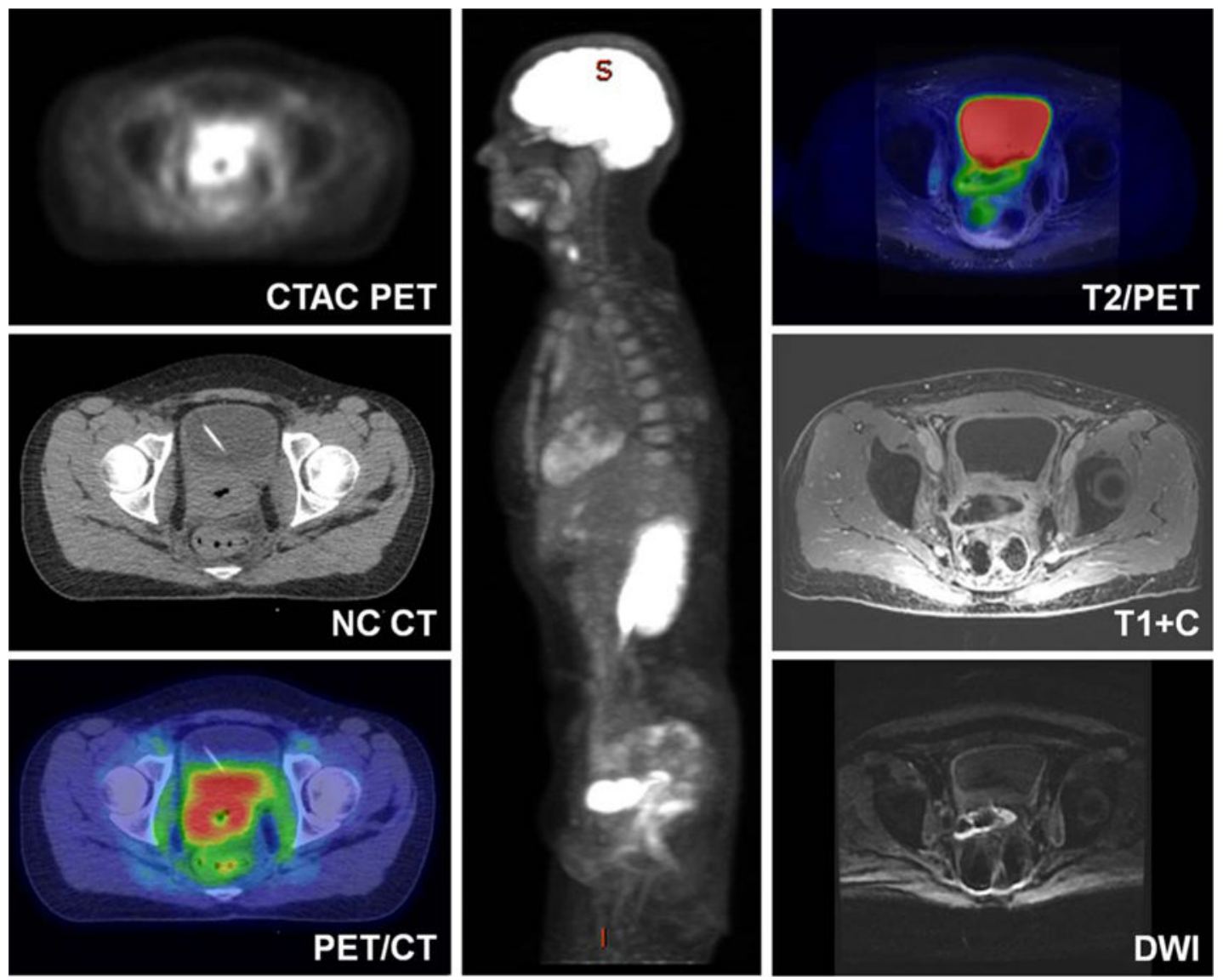

FIGURE 9.

A 29-year-old woman with history of squamous carcinoma of the cervix status post radiotherapy with an enlarging potentially necrotic FDG avid pelvic mass seen on noncontrast PET/CT (left images). PET/MRI was obtained for better soft tissue delineation before an expected pelvic exenteration. PET/MRI images (center and right) more clearly demonstrate a rim enhancing cavity, without significant enhancing nodularity or reduced diffusion (bottom right) in the wall. Based on these findings, the patient was taken for an examination under anesthesia and biopsy, which returned inflammatory tissue without evidence of recurrence, saving the patient a surgical resection. 

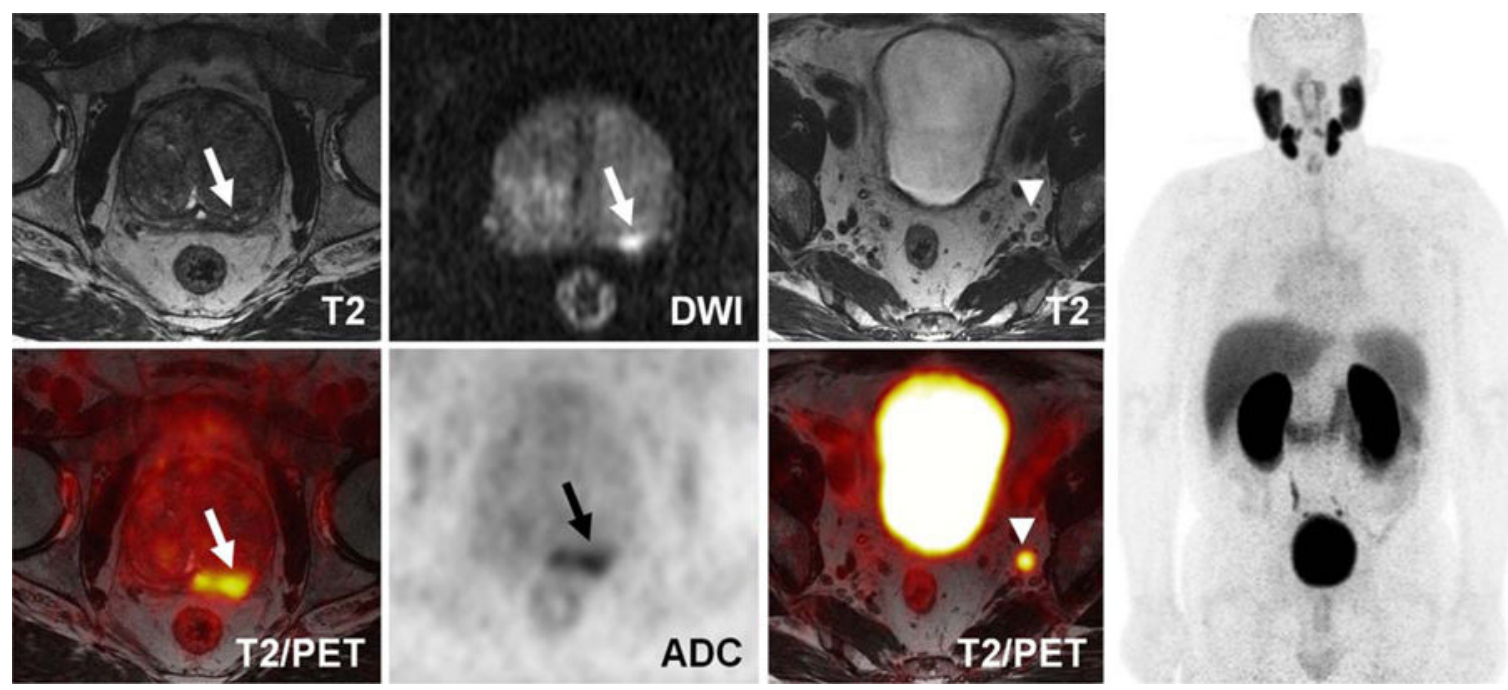

\section{FIGURE 10.}

Images from a 68-year-old man with PSA of 19.1 found to have Gleason $4+3$ prostatic carcinoma at biopsy. Combined whole body 68-Ga PSMA PET/MRI with dedicated prostate MRI performed for initial staging demonstrates an area of T2 hypointensity, diffusion restriction, and PSMA uptake in the left peripheral zone (arrows). T2 images of the pelvis demonstrate a small left internal iliac chain node (arrowheads), which appears normal in size and morphology but has PSMA uptake, suspicious for metastatic disease. 

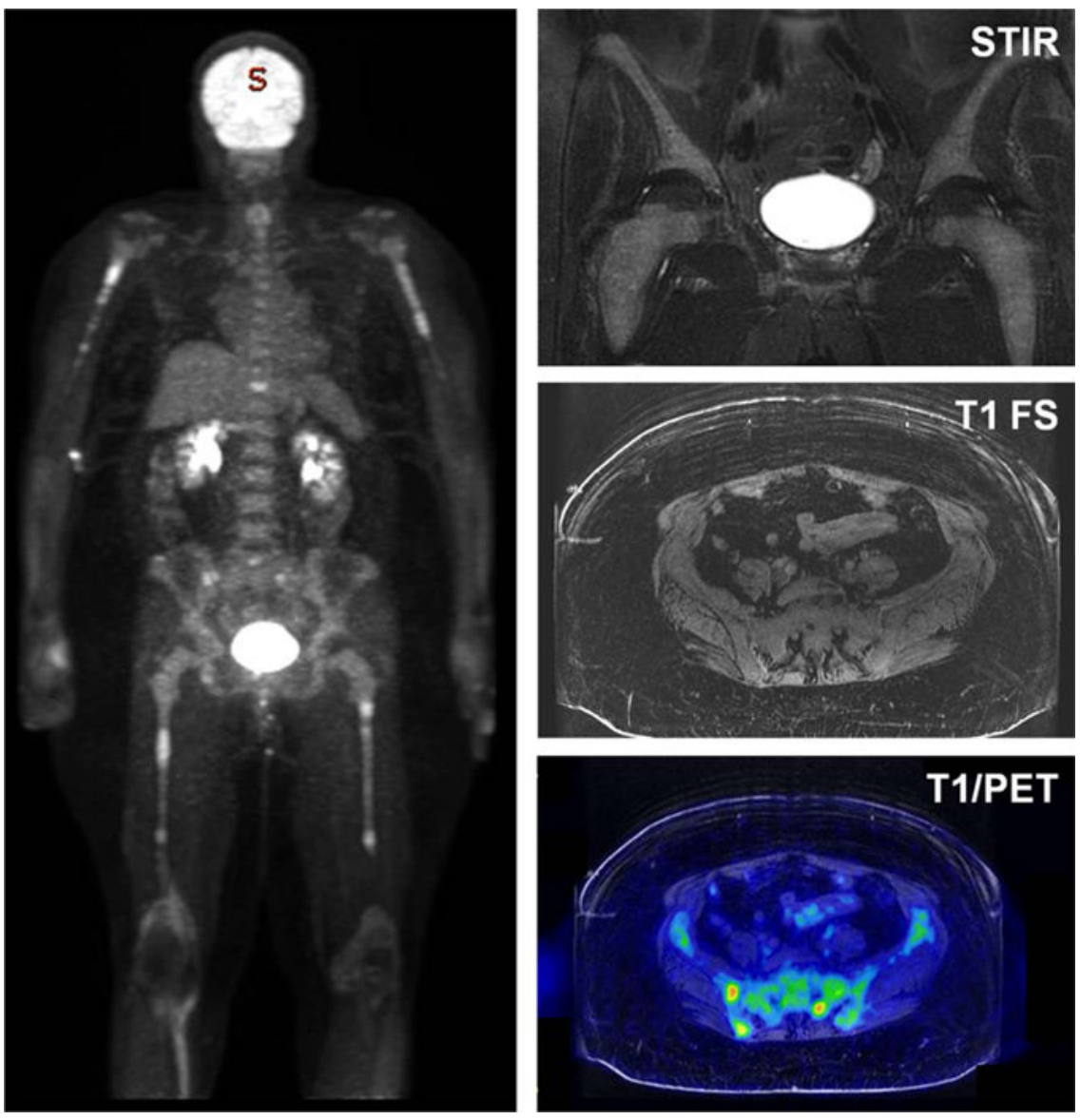

FIGURE 11.

FDG PET/MRI performed in a 62-year-old woman with biopsy proven multiple myeloma. MIP image (left) shows a pattern of bone marrow hyperplasia in the proximal humeri and femora, with superimposed focal areas of hypermetabolism throughout the axial and appendicular skeleton. Coronal STIR and axial T1 images (top and middle right) show diffuse marrow replacement without focal lesions. Fused FDG PET and axial T1 image (bottom right) shows multiple foci of disease within the right iliac bone and left sacrum, which were not seen on anatomic imaging alone. 


\section{Dixon pseudoct}

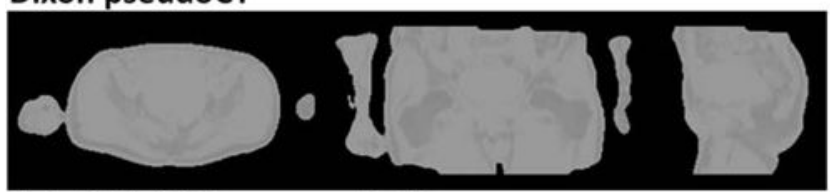

Hybrid ZTE/Dixon pseudoCT
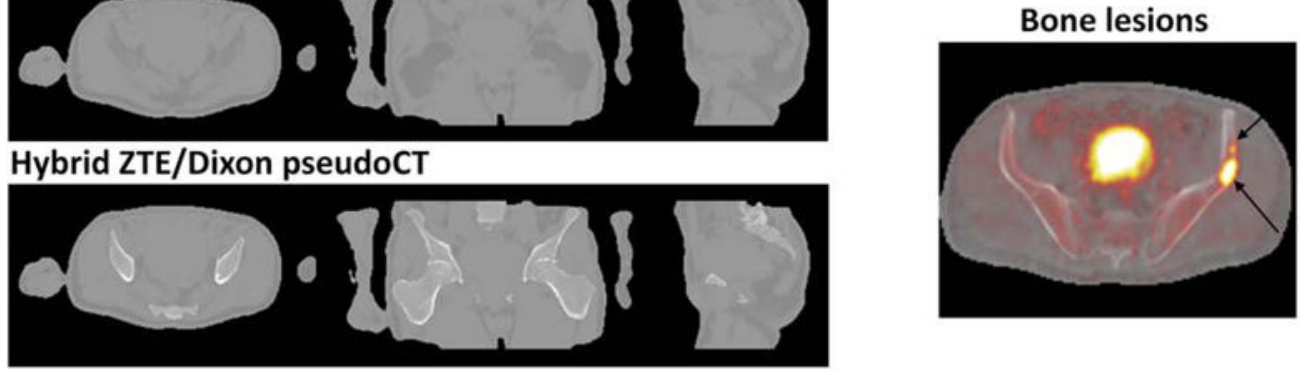

Soft tissue lesions

Dixon MRAC - CTAC
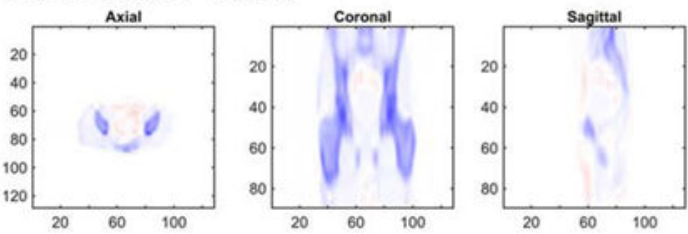

Hybrid ZTE/Dixon MRAC - CTAC

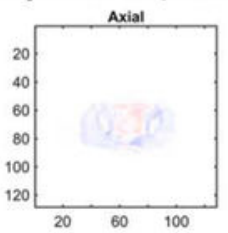

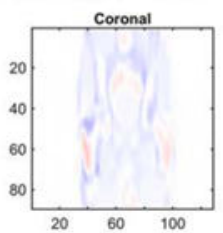

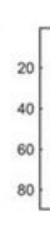

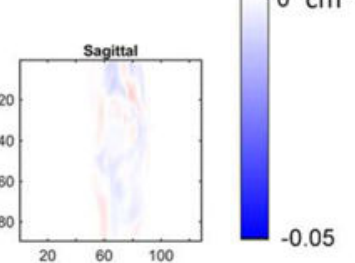
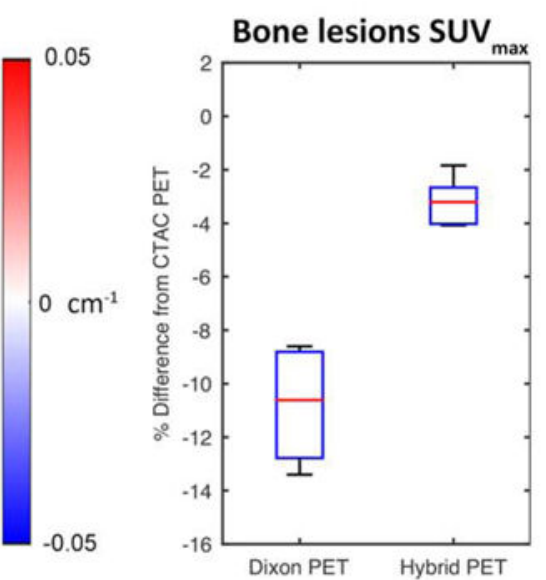

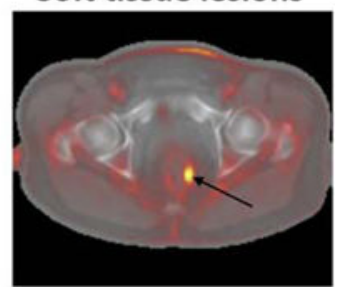

Soft tissue

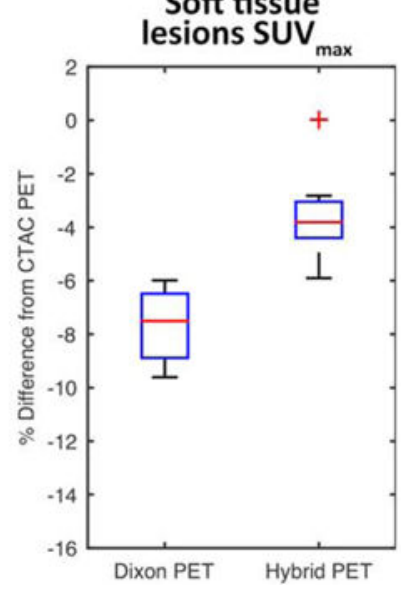

FIGURE 12.

PET/MRI attenuation correction in the pelvis: MR attenuation correction (MRAC) methods in the body currently use Dixon fat/water separation techniques that neglect bone, which leads to substantial errors $(>10 \%)$ for lesions within bone or soft tissues of the pelvis due to extensive surrounding bone. Preliminary results indicate that bone density can be accurately estimated from zero echo time (ZTE) MRI using a hybrid ZTE/Dixon method for pseudoCT (top left) and that MRAC is more accurate than Dixon alone compared with gold-standard CT attenuation correction maps (CTAC, bottom left). Preliminary results also indicate that these techniques can reduce average SUVmax errors of bony and soft tissue pelvic lesions to less than $5 \%$ (right). 
TABLE 1

\section{Comparison of PET/CT and PET/MRI}

\begin{tabular}{|c|c|c|}
\hline & Strengths & Limitations \\
\hline $\mathrm{PET} / \mathrm{CT}$ & $\begin{array}{l}\text { - Widely available } \\
\text { - Established imaging protocols } \\
\text { - Evidence proven indications } \\
\text { - Familiarity among ordering providers } \\
\text { - Quantitative accuracy well established } \\
\text { - Imaging of small pulmonary nodules } \\
\text { - Exams performed in as little as } 30 \text { minutes }\end{array}$ & $\begin{array}{l}\text { - Limited soft tissue contrast } \\
\text { - Fast CT exam does not provide extra time for PET acquisition } \\
\text { - IV contrast not routinely used } \\
\text { - If focused MRI needed, must be additional exam } \\
\text { - Ionizing radiation from CT component }\end{array}$ \\
\hline PET/MRI & $\begin{array}{l}\text { - Improved soft tissue contrast } \\
\text { - Added value of DWI } \\
\text { - Increased available time to collect PET data } \\
\text { - Better motion correction } \\
\text { - Convenience and time savings with combined exams } \\
\text { - Use of MRI specific contrast agents } \\
\text { - No ionizing radiation from MRI component }\end{array}$ & $\begin{array}{l}\text { - Limited availability } \\
\text { - Protocols and indications still in development } \\
\text { - Require technologist knowledgeable in both NM and MRI } \\
\text { - Quantitative accuracy still being determined } \\
\text { - Exams may take } 1 \text { hour or longer } \\
\text { - Limited evaluation of pulmonary parenchyma }\end{array}$ \\
\hline
\end{tabular}

$\mathrm{NM}=$ Nuclear Medicine. 